\title{
EFECTOS DEL BREXIT EN EL ÁMBITO DE LA POLÍTICA CRIMINAL DE LA UNIÓN EUROPEA Y DE REINO UNIDO
}

\author{
MARÍA ACALE SÁNCHEZ \\ Universidad de Cádiz \\ maria.acale@uca.es
}

\author{
Cómo citar/Citation \\ Acale Sánchez, M. (2018). \\ Efectos del brexit en el ámbito de la política criminal \\ de la Unión Europea y de Reino Unido. \\ Revista de Derecho Comunitario Europeo, 59, 97-142. \\ doi: https://doi.org/10.18042/cepc/rdce.59.03
}

Resumen

La decisión adoptada por Reino Unido de abandonar la Unión Europea ha despertado su preocupación por seguir ofreciendo seguridad a los mercados, para salvar la economía, relegando a un segundo plano en este primer momento de las negociaciones otras cuestiones muy relevantes, como las referidas a las materias penales. En este trabajo se analizan esencialmente las consecuencias que ese proceso va a causar sobre las materias político-criminales sustantivas como en los delitos de terrorismo, el

1 Catedrática de Derecho Penal de la Universidad de Cádiz. Este trabajo ha podido concluirse gracias al disfrute de la beca de la Fundación Salvador de Madariaga, que me ha permitido realizar una estancia de investigación en la Facultad de Derecho de la Universidad de Leicester durante los meses de agosto, septiembre y octubre de 2017. Quiero agradecer a Pablo Cortés, Chair in Civil Justice de esa Universidad, la amable y eficaz acogida dispensada. 
blanqueo de capitales, el fraude a los intereses económicos de la Comunidad, los delitos informáticos o la corrupción, desde una doble perspectiva: en primer lugar, para la política de la Unión Europea, que pierde a uno de sus miembros y por tanto se ve privada de sus aportaciones, y para Reino Unido, que debe revisar su ordenamiento jurídico depurándolo de aquellas leyes que hayan dejado de ser necesarias. En este proceso, Reino Unido deberá decidir si, a pesar de todo, la política criminal europea puede seguir influyendo en sus futuras decisiones judiciales y/o parlamentarias.

\title{
Palabras clave
}

Brexit; delitos; prevención; criminalidad; cooperación judicial; política criminal; derecho penal.

\section{CONSEQUENCES OF BREXIT ON THE CRIMINAL POLICY OF THE EUROPEAN UNION AND UNITED KINGDOM}

\begin{abstract}
British politicians are worried about the consequences that Brexit may have for their domestic market and want to offer economic security to business, but in this first moment of negotiations they have not accounted for the effect on political criminal law. This article analyses the effects of Brexit on criminal matters, such as terrorism, money laundering, fraud concerning the economic interests of the European Union, cybercrime and corruption. Two perspectives will be considered: the perspective of the European Union, that will lose one member (UK) and its opinions, and that of the UK, that must revise its laws and remove those no longer relevant after Brexit. However, the UK must decide if the European Union's criminal law could continue having an influence on their future judicial or parliamentary decisions.
\end{abstract}

\section{Keywords}

Brexit; crimes; prevention; criminality; juridical cooperation; criminal policy; criminal law.

\section{LES EFFETS DU BREXIT DANS LE DOMAINE DE LA POLITIQUE CRIMINELLE DE L'UNION EUROPÉENNE ET DU ROYAUME-UNI}

\section{Résumé}

La décision adoptée par le Royaume-Uni d'abandonner l'Union Européenne a soulevé sa préoccupation pour continuer à offrir la sécurité des marchés, pour sauver l'économie, reléguant dans ce premier moment des négociations à un deuxième plan 
d'autres questions fondamentales, comme celles qui se réferent aux matières pénales. Dans ce travail nous analysons essentiellement les conséquences que ce processus va causer en matières des normatives politico-criminelles comme les délits de terrorisme, le blanchiment de capitaux, les fraudes aux intérêts économiques de la Communauté, les délits informatiques ou la corruption. Nous aborderons ces conséquences d'une double perspective: d'une part, du point de vue de la politique de l'Union Européenne qui perd un de ses membres et se voit donc privée de ses apports et, d'une autre, celui du Royaume-Uni, qui doit réviser son ordre judiciaire le dépurant des lois qui ne sont plus nécessaires. Tout au long de ce processus, le Royaume-Uni devra décider si, malgré tout, la politique criminelle européenne peut continuer à influencer ses futures décisions judiciaires ou parlementaires.

\section{Mots clés}

Brexit; délits; prévention; criminalité; coopération judiciaire; politique criminelle; droit pénal. 


\section{SUMARIO}

I. PRESENTACIÓN. II. LA CARTA DE DESCONEXIÓN DE REINO UNIDO DE LA UE Y SU HOJA DE RUTA. III. LAS CUESTIONES PENALES Y PROCESALES QUE DAN FORMA A LA POLÍTICA CRIMINAL EUROPEA. IV. LA COOPERACIÓN EN MATERIA PENAL: 1. La prevención de la delincuencia, el racismo y la xenofobia. 2. Aproximación de las legislaciones penales: 2.1. Preliminares. 2.2. Delitos de terrorismo. 2.3. Delitos de blanqueo de capitales y falsificación de medios de pago. 2.4. Delitos de corrupción pública, fraude de los intereses financieros de la Unión y delincuencia organizada. 2.5. Delitos informáticos. V. APROXIMACIÓN A LOS ASUNTOS RELATIVOS A LA COOPERACIÓN EN MATERIA PROCESAL: 1. Principio de reconocimiento mutuo de resoluciones judiciales. 2. Organismos propios de la UE para luchar contra el delito. VI. EL LIMITADO CONTENIDO ESTRICTAMENTE PENAL DE LOS ACUERDOS PREVIOS AL TRATADO DE DESCONEXIÓN. VII. LOS EFECTOS DEL BREXIT EN EL SISTEMA ACTUAL DEL COMMON LAW. VIII. REFLEXIONES FINALES. BIBLIOGRAFía.

\section{PRESENTACIÓN}

La Revista de Derecho Comunitario Europeo de 2005, en su número de enero-abril, publicaba un artículo de Terradillos Basoco titulado «La Constitución para Europa: un reto político-criminal». En el trabajo, que se sitúa cronológicamente después del referéndum sobre la Constitución para Europea, el autor va recorriendo las distintas fases que hasta ese momento se habían sucedido hasta llegar la construcción de la UE con el desafío de "[...] sustituir el modelo legal propio de la Europa de los mercaderes, centrado en la protección fundamentalmente administrativa de los intereses económicos de la Unión, por otro modelo penal de ambiciosa tutela de bienes jurídicos identificados más que con intereses, con derechos subjetivos, con principios y con valores, por más que seamos conscientes de las limitaciones del Derecho penal al respecto» (Terradillos Basoco, 2005: 42). Por entonces, Europa asistía a un fenómeno transformador en virtud del cual la reticencia soberanista a ceder competencias penales a la UE se sustituía pragmáticamente por un incipiente núcleo de derecho penal orientado desde la misma UE, que había ido madurando y en su interior se había ido solidificando la idea de que la entidad 
alcanzada había llegado al punto de poder identificar necesidades, intereses y/o bienes jurídicos propios, como los relativos a su economía y sus finanzas, pero también de poder identificar otros bienes jurídicos de tanta trascendencia para la propia Unión y para la vida de la ciudadanía que podían ya referirse a ellos como si fueran propios también: es el caso del medio ambiente, la salud pública o la seguridad individual y colectiva frente a los ataques terroristas. El peso de estos nuevos bienes jurídicos convirtió el problema de la soberanía en una cuestión sencillamente «obsoleta» (Ouwerkerk, 2015: 31).

El rechazo entonces por parte de la ciudadanía francesa y la holandesa al tratado por el que se instituía una Constitución para Europa, obligó a los líderes europeos a cambiar si no el rumbo, sí la embarcación con la que se estaba llevando a cabo semejante singladura por otra más práctica que renunciaba al terciopelo de las banderas y los himnos, así como a la ambición política de la aprobación de «leyes europeas» (Acale Sánchez, 2008: 350).

Fruto de ese vaivén, el 13 de diciembre de 2007 vio la luz el Tratado de Lisboa, que en lo que aquí interesa dio un empuje considerable a la aprobación de normas europeas en la forma de directivas con indicaciones penales a los Estados miembros. Así, el título V TFUE, en la versión dada por aquel, contiene previsiones específicas de naturaleza penal, con la finalidad de "garantizar un nivel elevado de seguridad». Dicho objetivo se prevé alcanzar a través de un conjunto de medidas distribuidas en cuatro niveles: el primero lo ocupan las medidas de "prevención de la delincuencia, el racismo y la xenofobia y la lucha contra ellos»; el segundo las de «coordinación y cooperación entre autoridades policiales y judiciales»; en tercer lugar se encuentran las medidas de "reconocimiento mutuo de decisiones judiciales en materia penal», y finalmente «si es necesario, mediante la aproximación de las legislaciones penales» (Ramses y Marín, 2011: 272). Se trata de disposiciones de naturaleza penal y/o procesal de indudable calado, que han obligado a los Estados a considerar delictivas una pluralidad de conductas y a imponerles determinadas sanciones ${ }^{2}$. Muy lejos quedaban ya aquellos momentos en los que la incidencia del viejo derecho comunitario en cada uno de los códigos penales de los Estados miembros debía buscarse a través de las leyes penales en blanco o de las causas de justificación (Acale Sánchez, 2008: 351).

Aun así, con el Tratado de Lisboa, Reino Unido forzó la aprobación del Protocolo 21 «Sobre la posición del Reino Unido y de Irlanda respecto del espacio de libertad, seguridad y justicia», en cuya virtud, y según establece

2 Sanciones penales que, como se repite en las directivas y decisiones marcos de referencia, han de ser «efectivas, proporcionadas y disuasorias», como señalaba la STJUE de 15 de septiembre de 2005. Véase Acale Sánchez (2008: 349-380). 
el art. 1, ninguno de los dos países «[...] participarán en la adopción por el Consejo de medidas propuestas en virtud del Título $\mathrm{V}$ de la tercera parte del TFUE», autorizándoles el art. 3 a «notificar por escrito al Presidente del Consejo, en un plazo de tres meses a partir de la presentación al Consejo de una propuesta o iniciativa en virtud del Título $\mathrm{V}$ de la tercera parte del TFUE, su deseo de participar en la adopción y aplicación de la medida propuesta de que se trate, tras lo cual dicho Estado tendrá derecho a hacerlo» (Weyembergh, 2017: 287). No es necesario recordar que el título V de la tercera parte del TFUE es el referido al área de libertad, seguridad y justicia que condensa la parte más amplia de contenido penal del tratado. De esta forma, se produjo una entrada privilegiada ${ }^{3}$ de Reino Unido - y de Irlanda- en el Tratado de Lisboa ${ }^{4}$ : «a la carta» o "caso por caso» ${ }^{5}$, frente al menú que se le sirvió al resto de comensales de los Estados miembros. No hay muchas dudas sobre el motivo que llevó a Reino Unido a objetar el contenido del título V del tratado entonces (Mitsilegas, 2016; 2017a: 224-229): su elevada autoestima y la sobreacentuación de su soberanía, en virtud de la cual quiere seguir decidiendo sobre las materias esenciales, entre las que incluye las de naturaleza penal (Mitsilegas, 2017a: 224; Weyembergh, 2017: 285).

A raíz de ese Protocolo 21 se aprobó la Decisión de la Comisión de 1 de diciembre de 2014 (2014/858/UE) ${ }^{6}$ relativa a la notificación por parte de Reino Unido y de Irlanda de su deseo de participar en actos de la Unión en el ámbito de la cooperación policial y judicial en materia penal adoptados antes de la entrada en vigor del Tratado de Lisboa y que no forman parte del acervo de Schengen, a través de la cual ambos países admitieron vincularse por un total de veintinueve instrumentos legislativos en materias como la lucha contra la delincuencia organizada, la pornografía infantil, las formas de delincuencia graves, el decomiso de activos o las penas económicas. En este sentido, la vinculación o no de Reino Unido por la legislación penal de la UE anterior al Tratado de Lisboa pasa por el estudio del anexo de dicha decisión (Card y Molloy, 2014: 22).

Pues bien, años después del Tratado de Lisboa, Reino Unido ha decidido poner en marcha la vía que señala el art. 50 TUE, que contempla la posibilidad de que cada Estado pueda pedir su desconexión cuando lo estime

3 Como «ambigua», califica dicha entrada Weyembergh (2017: 287).

4 Además de Dinamarca, que según el Protocolo 22 también se vinculará por las decisiones europeas relativas al título $\mathrm{V}$ "cuando sea posible de conformidad con sus normas constitucionales».

5 O pick-and-choose approach: véase Mitsilegas (2017a: 246).

6 DO 359, L. 345/6, de 1 de diciembre de 2014 (p. 30). 
pertinente ${ }^{7}$ y salirse del todo de esa estructura supranacional, a través de un proceso que comenzó con un referéndum y que ante la complejidad de las negociaciones puede ver retrasada su culminación: el brexit. El apdo. 2 del art. 50 señala los pasos que deben ir dando el Estado que quiera retirarse y la UE a través del Consejo para alcanzar un acuerdo que establezca «la forma de su retirada, teniendo en cuenta el marco de sus relaciones futuras con la Unión». Dicho acuerdo, que se negociará según lo establecido en el apdo. 3 del art. 218 TFUE, deberá ser posteriormente aprobado por el Parlamento.

El paso dado por Reino Unido ha sembrado una gran incertidumbre en el panorama europeo. Lo que sí parece claro es que en su decisión no ha pesado el hecho de que anteriormente cediera soberanía en materia penal, pues en esencia y con carácter general no la cedió con la firma del Tratado de Lisboa del que ahora se desvincula completamente. Por tanto, los motivos deben haber sido distintos.

En cualquier caso, su importancia no puede negarse, aunque antes de este momento Reino Unido venía dando pistas sobre la falta de interés en la construcción de una Europa —en teoría— libre, segura y justa, al tiempo que, por otra parte, rechazaba la moneda única ${ }^{8}$. Puede decirse que uno y otro son datos que venían a poner de manifiesto la fragilidad de una Unión que podía romperse en cualquier momento?.

Ahora lo que preocupa es que la salida de la Unión de uno de los países miembros más relevantes puede terminar afectando al modelo construido, en la medida en que haya otros Estados pendientes de este proceso para emprender posteriormente su propio camino de exit (Jimeno-Bulnes, 2017: 329).

7 Como afirma Jimeno-Bulnes (2017: 326), esa ley del Parlamento británico era necesaria para derogar la European Communities Act de 1972. Véase Quintero Olivares (2017: 166).

8 Como recuerdan Mangas y Liñán (2015: 35), las relaciones de Reino Unido con la Unión Europea han sido difíciles desde el principio. Así, recuerdan ya la desconfianza de Francia en 1967 al «compromiso europeo de los británicos», así como el hecho de que en 1974 el Partido Laborista ganara las elecciones «con la promesa electoral de celebrar un referéndum para salir de las Comunidades», el cual se celebró pero en esa ocasión el pueblo de Reino Unido apoyó la permanencia.

9 Con razón ha definido la situación de Reino Unido Mitsilegas (2016: 44) como una justicia a la carta. Jimeno-Bulnes (2017: 329) recoge esa definición. En esta línea inciden las propuestas realizadas por la Law Society of England and Wales, en enero de 2017, en su documento «Brexit and the Law». Disponible en https:/goo.gl/U9q31n (fecha de la última consulta: 16-10-2017). 


\section{LA CARTA DE DESCONEXIÓN DE REINO UNIDO DE LA UE Y SU HOJA DE RUTA}

El 29 de marzo de 2017, la primera ministra enviaba una carta al presidente del Consejo Europeo comunicándole que tras el resultado del referéndum del 23 de junio de 2016, el pueblo de Reino Unido había decidido abandonar la UE ${ }^{10}$, y que el 26 de marzo de 2017 el Parlamento acababa de aprobar la ley en la que se convalidaba el resultado del referéndum. A partir de ese momento se ha puesto en marcha un proceso cuya finalidad es llegar a un acuerdo sobre las condiciones de la desconexión en un plazo de dos años que puede ser prorrogado ${ }^{11}$ ante las previsibles dificultades existentes (art. 50 TUE). En cualquier caso, la ruptura difícilmente podrá producirse un día determinado a una concreta hora, una vez se apruebe finalmente el tratado de desconexión, en la medida en que no es fácil poner límites al uso de datos, así como a compromisos políticos y económicos que tienen una planificación plurianual.

Invertir el proceso emprendido resulta a priori y teóricamente muy difícil. No obstante, cabría plantearse la posibilidad de que Reino Unido, antes de que se firmen los acuerdos finales, volviera a someter a referéndum su mantenimiento dentro de la UE y la ciudadanía cambiara de opinión. Sin embargo, en este punto puede decirse que la sociedad inglesa se encuentra dividida: basta ver los encendidos debates mantenidos en televisión o las columnas de opinión en la prensa, en las que por una parte un sector de la población se siente apesadumbrado por las puertas que se les cierran con la salida de la UE, mientras otro sector mira el proceso con mucho optimismo, porque entiende que esas mismas puertas que cerrarán sus fronteras van a poner fin al desempleo que sufre la población británica, que hoy acusa a la UE de haberle dejado sin trabajo al admitir la libre circulación de trabajadores. Este sector de la población no tiene en cuenta el hecho de que en Reino Unido existe un elevado número de personas inmigrantes que no provienen de la UE sino de terceros países no afectados por el brexit, así como tampoco valora el contingente de trabajadores ingleses que trabaja en otros países de la Unión, que también

10 Véase el análisis que realiza de los resultados del referéndum Leonard (2017: 6).

11 El Acuerdo 21009/17 con las Directives for the negotiation of an agreement with the United Kingdom of Great Britain and Northern Ireland setting out the arrangements for its withdrawal from the European Union (disponible en: https://goo.gl/cvnM1E, fecha de la última consulta: 23-10-2017) lo fija en el 30 de marzo de 2019, a no ser que ambas partes decidan su prórroga llegado el momento. 
puede verse en la obligación de volver a su país ${ }^{12}$. Mientras tanto, el diario The Independent afirmaba el pasado 7 de julio que después del brexit se ha producido el mayor incremento del número de delitos de odio por razones religiosas y raciales "jamás registrado» ${ }^{13}$, favorecido por el clima pronacionalista que defiende el sector de la población partidario de fortificar las fronteras inglesas. Conseguir que ese nivel de delitos de odio disminuya ${ }^{14}$ es una tarea pendiente a la que urge hacer frente, y el retraso de la firma del acuerdo final de salida no favorece la solución del problema discriminatorio detectado ${ }^{15}$.

En esa carta, Theresa May presenta la decisión de abandonar la UE con un discurso que quiere transmitir la idea de seguridad, pero también deja ver - a pesar de la mano dura con la que esas palabras están escritas - las inseguridades inherentes al complejo proceso que estaba poniendo en marcha. La frase «nos vamos de la UE, pero no de Europa; y queremos seguir siendo unos socios y aliados comprometidos con nuestros amigos de todo el continente» viene a resumir esos miedos ante el rechazo o la incomprensión de esa decisión en el seno de la UE. Ahora bien, si nos preguntamos qué es a día de hoy Europa si le quitan la UE, cuando los países europeos que no son Estados miembros mantienen acuerdos interesados con ella, la afirmación de May no es más que un galimatías.

Al margen ya de los ejes que han centrado esta primera ronda de las negociaciones ${ }^{16}$, del tenor de la carta de May se desprenden tres preocupaciones esenciales. La prioritaria es ofrecer protección a la ciudadanía de la UE y de Reino Unido, señalando que «debemos tratar de llegar pronto a un acuerdo sobre sus derechos», con lo que se reconoce que el brexit lleva consigo aparejado un cambio cualitativo y/o cuantitativo tanto para los ciudadanos de la Unión que viven en Reino Unido como para los de Reino Unido que viven en la UE. A partir de aquí, en segundo lugar, puede decirse que el resto del mensaje se centra en la preocupación por ofrecer estabilidad y seguridad a los negocios y a las empresas, en lo que se insiste en varias ocasiones, al punto de

12 Por ejemplo, véanse las cifras de españoles que residen en Reino Unido y de ingleses que residen en España, que maneja Leonard (2017: 1-2).

13 Artículo disponible en: https://goo.gl/5hYeK4.

14 Lo que favorecería que se dejara de identificar el rostro de las personas extranjeras con el brexit.

15 El seguimiento de los asuntos relacionados con el brexit por parte de los principales periódicos es diario. Puede hacerse una comparación de las noticias en The Guardian. y en The Telegraph, de orientación política distinta.

16 Que se han limitado a analizar las cuestiones relativas a los derechos de los ciudadanos y las relaciones familiares, las relaciones con Irlanda del Norte y el cálculo del coste financiero de la salida. 
permitirnos sacar la conclusión de que en el fondo, en la conciencia de Reino Unido, pesa más la vieja Europa de los mercaderes, que la moderna Europa de la ciudadanía (Terradillos Basoco, 2005: 42). Y la tercera preocupación tiene que ver con la seguridad, al afirmar que «debilitar nuestra cooperación en pos de la prosperidad y la protección de nuestros ciudadanos sería un error muy costoso ${ }^{17}$, enfatizando la conveniencia de firmar un acuerdo específico sobre este punto sobre el que se ha debatido ampliamente en la Cámara de los Lores y en la Cámara de los Comunes ${ }^{18}$. Todo apunta en este sentido a que se está haciendo referencia a los organismos de la UE de lucha contra el delito como Europol o Eurojust, pero nada más se dice sobre la protección de bienes jurídicos que Reino Unido había emprendido de acuerdo con las indicaciones de la UE, ni a la protección que en Reino Unido se ofrece a los intereses de la Unión.

La falta de visibilización de los aspectos estrictamente penales en la carta se constata de nuevo cuando se examinan las previsiones específicas para las materias de cooperación judicial en materia civil y mercantil, de las que se excluyen las de naturaleza penal ${ }^{19}$ : en su virtud, el acuerdo no garantiza el reconocimiento y ejecución de las decisiones judiciales nacionales en materia de cooperación judicial penal que permanezcan reguladas por el derecho de la Unión. Aquella discusión habida en los momentos iniciales de la puesta en marcha de la Unión puede estar determinada ahora por el hecho de que no se

17 En este sentido, los trabajos en comisión en materia financiera han sido los primeros que han ido dando resultados, a la vista de la complejidad que encierran. Basta leer la Position Paper "Essential Principles on Financial Settlement», TF 50 (2017) 2/2-Commision to United Kingdom, de 12 de junio. Disponible en: https://goo.gl/cvnM1E (fecha de la última consulta: 23-10-2017), en el que se establece una separación entre los gastos que van a pasar a ser solo de la Unión Europea y los gastos que serán compartidos por ambos, de acuerdo con el programa de financiación para el período 2014-2015. $\mathrm{El}$ acuerdo tiene un anexo con una lista indicativa de los organismos y fondos que se incluyen en el marco de la financiación, entre los cuales se encuentran Eurojust y Europol, a los que posteriormente se volverá a hacer referencia.

18 Puede consultarse en la siguiente dirección: https://goo.gl/cYcoVy.

19 «En relación con la cooperación judicial en materias civiles y mercantiles entre Reino Unido y los 27 países de la Unión Europea, el acuerdo puede garantizar que el reconocimiento y ejecución de las decisiones judiciales nacionales tomadas antes de la fecha de salida permanezcan gobernadas por las relevantes provisiones del Derecho de la Unión aplicable antes de la fecha de salida. El acuerdo podrá también asegurar la continua aplicación de las reglas del Derecho europeo en relación con las opciones del fórum y opciones de la ley hechas antes de la fecha de salida». 
discuta sobre si las competencias penales vuelven a Reino Unido, con independencia de que, como se verá a continuación, la cesión británica no fue tal.

La carta concluye afirmando con un evidente pragmatismo que la legislación de la UE derogada se convertirá en leyes de Reino Unido «cuando ello resulte práctico y adecuado», con la finalidad de evitar vacíos legales que generen inseguridad para las empresas y un sentimiento de impunidad para quienes intenten aprovechar la ocasión para lucrarse. En este sentido, el pasado 12 de septiembre el Parlamento británico dio el primer paso para "nacionalizar» el derecho de la $\mathrm{UE}^{20}$. Con todo, queda la duda sobre si la legislación europea será utilizada como práctico comodín ocasional o si, transcurrido el tiempo necesario para que después del brexit Reino Unido ponga al día su articulado, permanecerá la esencia de la política criminal europea.

El 3 de mayo la Comisión Europea publicaba su decisión de autorizar a la Comisión a abrir las negociaciones sobre el acuerdo de retirada (Com 2017/218 final) ${ }^{21}$, en atención a las previsiones establecidas en el art. 50 del TUE, paso que tenía que darse así una vez recibida la carta de Reino Unido el 29 de marzo. El 22 de mayo de 2017 el Consejo de la UE publicaba el Acuerdo 21009/17 con las directrices para la negociación del acuerdo con el Reino Unido de Gran Bretaña y el norte de Irlanda sobre la retirada de la UE ${ }^{22}$. En el punto 13 se refiere a la necesidad de que los acuerdos de retirada abarquen las materias de procedimientos de cooperación judicial, «incluidos los procesos de cooperación judicial en materia civil, mercantil y penal, así como administrativa y procedimientos de cooperación procesal», procedimientos «penales» a los que no hizo referencia Theresa May en su carta.

El 19 de junio de 2017 la Comisión Europea, en nombre de la UE, acuerda con Reino Unido el timetable así como la forma de trabajo ${ }^{23}$. Las fechas de las reuniones programadas eran 19 de junio, 17 julio, 28 agosto, 18 septiembre y 9 de octubre, sobre tres temas principales: derechos de los ciudadanos, acuerdo financiero y «otros problemas de la separación», aunque nada impedía añadir más temas. De todos ellos, aquí interesan especialmente aquellos que se refieren a las materias penales.

En el momento en el que se escriben estas páginas, han tenido ya lugar las reuniones originariamente previstas sin que se haya alcanzado el acuerdo

20 Véase toda la información que se ofrece en la web del Ministerio para la salida de la Unión Europea sobre la «Repeal bill»: https://goo.gl/jRUvrV (fecha de la última consulta: 10-1-2018).

21 Véase https://goo.gl/RKoJhK (fecha de la última consulta: 23-10-2017).

22 Ibid.

23 Ibid. 
definitivo, por lo que aún puede pasar cualquier cosa, incluso la salida no negociada.

Las incertidumbres que ha sembrado el brexit no son solo para la UE, que ve ahora cómo uno de sus miembros ha abierto la puerta de salida, sino para cada uno de los Estados miembros (Jimeno-Bulnes, 2017: 329), que tienen que replantearse sus relaciones individualmente con Reino Unido, sin el tamiz protector de aquella. Esto determina que con el brexit caen como fichas de un dominó las relaciones de Reino Unido con la UE y con los Estados miembros, pero también la de estos con aquel, obligados a volver a la vía de los acuerdos bilaterales sobre materias que son competencia de la UE ${ }^{24}$.

Alcanzar un acuerdo general entre UE y Reino Unido, tomando como modelos los ya existentes con Noruega y Suiza (Suominen, 2017: 251 y ss.; Meyer, 2017: 275 y ss.), no es tan sencillo, porque en estos casos se trata de Estados que, desde fuera de la UE — donde han estado siempre-, han alcanzado acuerdos en asuntos de común acuerdo. El caso de Reino Unido es distinto porque es un país que opta por salirse, pero una vez fuera, echa en falta la cobertura que tenía dentro. Y el resto de los Estados miembros pueden no estar dispuestos a "compensar» a Reino Unido con acuerdos que les beneficien puntualmente ${ }^{25}$, al entender que se "libera» de compromisos económicos muy exigentes y con el precio electoral que esas decisiones lleva aparejadas. A esto pudo estar refiriéndose la canciller Angela Merkel cuando afirmó que Alemania no iba a permitir que el brexit fuera una especie de «cosecha de cerezas» (Bock, 2017: 311), es decir, una salida del todo pero no de las partes individuales que le interese mantener. Por otra parte, al igual que hace la canciller alemana, aunque en sentido inverso, el ciudadano inglés de a pie puede interpretar que acuerdos futuros de mantener relaciones específicas y en asuntos predeterminados con la UE suponen una traición a su voluntad expresada en el referéndum, lo que les puede llevar en próximas citas electorales a cambiar el sentido de su voto.

Por eso, como afirma Bock, los acuerdos bilaterales que se firmen entre la UE y Reino Unido van a ser revisados con lupa por los países miembros, para los cuales puede ser cuestionable «si el acercamiento del sistema de

24 Pueden verse los siguientes trabajos sobre las consecuencias que el brexit trae consigo en el ámbito de las relaciones entre Reino Unido y distintos Estados miembros de la Unión Europea: Solar Calvo (2016); Jimeno-Bulnes (2017: 325 y ss.); Swiatlowska y Nita-Swiatlowska, (2017: 319 y ss.); Suominen (2017: 251 y ss.); Cahn (2017: 301 y ss.); Meyer (2017: 275 y ss.); Bock (2017: 311 y ss.).

25 Como resalta Weyembergh (2017: 295) el espíritu de «venganza» por parte de los Estados miembros hacia Reino Unido no va a facilitar una salida ordenada. 
cooperación con la UE puede ser extendido a un Estado que —en palabras de la canciller Merkel — ha decidido dejar la familia europea y haciendo así que se rompan los lazos de confianza que define esta familia» (Bock, 2017: 316).

La tarea que tiene pendiente Reino Unido es encomiable porque, en efecto, con independencia de que en este momento de la desconexión (y para evitar vacíos en un ordenamiento jurídico en el que las leyes escritas tienen como origen la necesidad de adaptarse a la normativa que iba emanando de la UE) apruebe con carácter urgente una suerte de convalidación a la inglesa y haciendo abstracción de su origen de esas normas, a medio plazo deberá tomar la decisión, cuando tenga tiempo suficiente para entrar a analizar la multitud de normas europeas que van a ser «soberanamente» nacionalizadas, de si da un giro a su política criminal o si nacionaliza la política criminal de la UE. De ser así, Reino Unido dejará de participar en la política criminal europea, pero la política criminal europea tendrá un notable peso en el ordenamiento jurídico inglés. Lo que sí parece claro es que la UE seguirá desarrollando su derecho penal «con una influencia menor de Reino Unido» (Mitsilegas, 2017a: 250), con independencia ya de los singulares acuerdos que se alcancen (Mitsilegas, 2017b: 438).

\section{LAS CUESTIONES PENALES Y PROCESALES QUE DAN FORMA A LA POLÍTICA CRIMINAL EUROPEA}

El análisis de los aspectos político-criminales del brexit está condicionado obviamente por lo que se entienda por tales, porque, como afirman Ambos y Bock, la referencia a «materias penales» viene siendo utilizada como una suerte de paraguas bajo el que se incluyen «normas y prácticas de leyes penales y político criminales basadas en la ley y en las actividades de la Unión dirigidas (o con la finalidad de dirigir) a la armonización generalizada de la ley (procesal) penal nacional ${ }^{26}$. Los autores enfatizan la necesidad de distinguir las normas de contenido penal de la UE y las normas que han tenido que ir aprobando los Estados miembros para dar el debido cumplimiento a aque$1 l a s^{27}$. Respecto a estas últimas, afirman que se trata de «normas nacionales influenciadas por el orden legal europeo» (Bock, 2017: 193). Esto determina

26 Véase también Ouwerkerk (2015: 25 y s.).

27 Véase Acale Sánchez (2008: 350), donde se afirma que la desaparición de las «leyes europeas a las que se refería La Constitución para Europa en el Tratado de Lisboa obligó a seguir en la búsqueda de un Derecho europeo penal, cruzando la senda que marca el actual —y limitado- Derecho penal europeo». 
pues que cuando se quiere conocer el alcance de la política criminal europea, es preciso realizar un acercamiento a las indicaciones penales que ha dirigido la Unión a los Estados miembros y simultáneamente a las normas aprobadas por cada Estado para adaptarse a aquellas.

Con todo, como se señalaba anteriormente, el título V TFUE brinda un concepto normativo de las «materias penales» o «materias político-criminales» en el sentido más amplio del término, que abarca la prevención de la delincuencia, la coordinación y cooperación entre autoridades policiales y judiciales, el reconocimiento mutuo de decisiones judiciales en materia penal y la aproximación de las legislaciones penales ${ }^{28}$. Aun así, como reconoció ya el Tribunal de Justicia de la UE en su ya vieja Sentencia 13.09.2005, Comisión/ Consejo, C-176/03 ${ }^{29}$, la UE puede adoptar «medidas relacionadas con el Derecho penal de los estados miembros y que estime necesarias para garantizar la plena efectividad de las normas que dicten", por lo que no todo el derecho penal proveniente de la UE tiene su fundamento en este título V.

La firma del Protocolo 21 del Tratado de Lisboa al que se hacía referencia anteriormente obliga a comprobar caso por caso si Reino Unido se ha vinculado o no a cualquiera de las directivas relativas al espacio de libertad, seguridad y justicia. Ahora bien, esto no significa que se haya desvinculado de los aspectos político-criminales de la UE en su totalidad por dos razones fundamentales. La primera, porque no todas las indicaciones penales aprobadas por la UE se basan orgánicamente en el título V TFUE. Y en segundo lugar, porque a través de la Decisión de la Comisión de 1 de diciembre de 2014 (2014/858/ UE) relativa a la notificación por parte del Reino Unido y de Irlanda del Norte de su deseo de participar en actos de la Unión en el ámbito de la cooperación policial y judicial en materia penal adoptados antes de la entrada del Tratado de Lisboa y que no forman parte del acervo de Schengen, como se decía anteriormente, admitieron vincularse por veintinueve instrumentos legislativos de contenido «altamente penal».

Antes de pasar a analizar esas concretas materias, es especialmente significativo el hecho de que no vayan a tratarse en estas páginas los efectos que el brexit puede tener sobre las víctimas de los delitos, a las que se refiere el art.

28 En efecto, esto es lo que se desprende del art. 67.3 TFUE: «La Unión se esforzará por garantizar un nivel elevado de seguridad mediante medidas de prevención de la delincuencia, el racismo y la xenofobia y de lucha contra ellos, medidas de coordinación y cooperación entre autoridades policiales y judiciales y otras autoridades competentes, así como mediante el reconocimiento mutuo de resoluciones judiciales en materia penal y, si es necesario, mediante la aproximación de las legislaciones penales». Sentencia del Tribunal de Justicia de 13 de septiembre de 2005, Comisión/Consejo, C-176/03. 
82.2 TFUE, en particular que no se haga mención a la Directiva 2011/36/ UE del Parlamento Europeo y del Consejo, de 5 abril de 2011, relativa a la prevención y lucha contra la trata de seres humanos y a la protección de las víctimas y por la que se sustituye la Decisión Marco 2002/629/JAI del Con$\operatorname{sejo}^{30}$, que se ha convertido en un instrumento que les ha permitido disfrutar de su derecho fundamental a la libre circulación por el territorio de la Unión, al contemplar mecanismos para apoyarlas y asesorarlas, en la medida en que en su considerando 35 afirma que «de conformidad con los artículos 1 y 2 del Protocolo sobre la posición del Reino Unido [...] no participa en la adopción de la presente Directiva, y no queda vinculado por la misma ni sujeto a su aplicación».

\section{LA COOPERACIÓN EN MATERIA PENAL}

\section{LA PREVENCIÓN DE LA DELINCUENCIA, EL RACISMO Y LA XENOFOBIA}

El art. 84 TFUE señala que «el Parlamento Europeo y el Consejo podrán establecer, con arreglo al procedimiento legislativo ordinario, medidas que impulsen y apoyen la actuación de los Estados miembros en el ámbito de la prevención de la delincuencia, con exclusión de toda armonización de las disposiciones legales y reglamentarias de los Estados miembros». Del tenor literal del precepto, llama la atención la angostura de la letra de la ley, esto es, la referencia a la "prevención de la delincuencia», omitiendo mención alguna a la sanción - aunque aparecen en el interior del Tratado--, a pesar de que es a través de ella como previene el derecho penal la delincuencia.

Las acciones en materia preventiva son difíciles de adoptar de forma separada de los mismos instrumentos a través de los cuales se aproximan las normas penales o de los que se ponen en marcha cuerpos oficiales de lucha contra la criminalidad, pues precisamente la finalidad que persiguen estas últimas es la de prevenir que las actividades delictivas objeto de referencia tengan lugar, luchando eficazmente contra ellas. Con todo, pueden encontrarse algunos documentos en los que «específicamente» la UE reflexiona y planifica su lucha contra la criminalidad: se trata de documentos que dan forma a la parte general de la prevención de la delincuencia y que posteriormente han demostrado tener un amplio recorrido. Entre ellos, la Comunicación de la Comisión al Consejo y al Parlamento Europeo sobre prevención de la

30 DO L 101, de 15 de abril de 2011, p. 1. 
delincuencia, ${ }^{31}$ define la prevención como «aquellas actividades que contribuyen a detener o reducir la delincuencia como fenómeno social, tanto cuantitativa como cualitativamente, ya sea a través de medidas de cooperación permanente y estructurada, o a través de iniciativas concretas». Se trata de una finalidad que no tiene por qué alcanzarse exclusivamente por medio del derecho penal, pues también están llamadas a hacerlo "la política social, la educación, el urbanismo, la fiscalidad, etc.», en la medida en que se trata de una rama del ordenamiento jurídico de cada país que ocupa el lugar último, la ultima ratio, también en el ámbito de las políticas de la UE debe dársele la oportunidad a los mecanismos de control previos. Posteriormente se aprobó la Decisión del Consejo de 12 de febrero de 2007, por la que se establece para el período 2007-2013 el programa específico «Prevención y lucha contra la delincuencia, integrado en el Programa general Seguridad y defensa de la libertad $\aleph^{32}$.

De todas las políticas de prevención de la delincuencia, el art. 67.3 TFUE pone especial atención en la prevención y lucha contra el racismo y la xenofobia. En este sentido, debe tenerse en consideración la Decisión Marco 2008/913/JAI relativa a la lucha contra determinadas formas y manifestación

31 Comunicación de la Comisión al Consejo y al Parlamento Europeo sobre prevención de la delincuencia. Reflexiones sobre unas orientaciones comunes y propuestas a favor del apoyo financiero comunitario de 2000 (52000DC0786) -COM/2000/0786 final. No está publicada en el DO. Puede verse en https:/goo.gl/iHsVke. Lo que en este momento quiere resaltarse es la importancia que tuvo este documento entonces, cuyo objetivo único y específico fue el lineamiento político-criminal de la Unión Europea en la prevención de la delincuencia. A posteriori, como es sabido, la Unión ha ido aprobando una pluralidad de directivas que tienen como objetivo la lucha contra la criminalidad en parcelas concretas: se trata de la parte especial de la prevención de la delincuencia en la Unión Europea. Entre ellas han de resaltarse la Directiva (UE) 2017/54 del Parlamento Europeo y del Consejo de 15 de marzo de 2017, relativa a la lucha contra el terrorismo (DO L 88, de 31 de marzo de 2017, p. 6), la Directiva 2011/36/UE del Parlamento Europeo y del Consejo, de 5 abril de 2011, relativa a la prevención y lucha contra la trata de seres humanos y a la protección de las víctimas y por la que se sustituye la Decisión Marco 2002/629/JAI del Consejo o la Directiva 2013/40/UE del Parlamento Europeo y del Consejo de 12 de agosto de 2013 relativa a los ataques contra los sistemas de información (DO L 127 de 29 de abril de 2014, p. 39), que a día de hoy son un buen ejemplo de aquella preocupación que se dejaba entrever en el año 2000, a través de un documento que ponía el acento en la prevención de la delincuencia más que en la lucha contra determinadas formas específicas de criminalidad.

32 DO L 58, de 24 de diciembre de 2007 (p. 7). 
del racismo y la xenofobia mediante el derecho penal ${ }^{33}$, que expresamente declara en su art. 12 que será aplicable en Gibraltar ${ }^{34}$.

En realidad, obviamente, la salida de Reino Unido de la UE no va a suponer que renuncie a prevenir la delincuencia, ni tampoco significa que esté en desacuerdo con las medidas adoptadas por la Unión, máxime cuando expresamente señala el art. 84 TFUE que la UE tiene excluida la posibilidad de la armonización de las legislaciones penales de los Estados miembros. Simplemente va a significar que Reino Unido no va a participar más en las reflexiones, ni en el diseño de estas estrategias y que la UE se va a ver privada de sus aportaciones ${ }^{35}$.

\section{APROXIMACIÓN DE LAS LEGISLACIONES PENALES}

\subsection{Preliminares}

Con mucha cautela, el art. 83.1 TFUE abre la vía a la aproximación de las legislaciones penales "si es necesario" ${ }^{36}$ en unas concretas parcelas de la criminalidad que se dejaban señaladas, convirtiendo así insistentemente a la política criminal europea en la ultima ratio, a partir de la cual llevar a cabo la aproximación de las legislaciones penales nacionales -que son las que se rigen por el principio de ultima ratio del Derecho penales ${ }^{37}$. Aun así, el elenco de "parcelas» a las que expresamente se refería el párr. 2 del art. 83.1 estaba redactado en términos lo suficientemente amplios como para garantizar una intervención — también — amplia de la Unión en materias penales: «El terrorismo, la trata de seres humanos y la explotación sexual de mujeres y niños, el tráfico ilícito de drogas, el tráfico ilícito de armas, el blanqueo de capitales, la corrupción, la falsificación de medios de pago, la delincuencia informática y la delincuencia organizada». Se trataba, por lo demás, de un elenco de materias

33 DO L 328/55, de 6 de diciembre de 2008 (p. 24).

34 En particular, sobre los efectos del brexit en Gibraltar, véase ampliamente Del Valle Gálvez (2017: 19-26).

35 Y de su experiencia, como subraya Weyembergh (2017: 298), en la lucha contra el terrorismo.

36 Como recuerdan Ambos y Bock (2017: 196), el recurso a la aproximación de las legislaciones penales se realiza «junto a la tradicional y más indirecta técnica de europeización» de la asimilación de las legislaciones penales, en virtud de la cual los Estados miembros vienen obligados a garantizar la misma protección a los intereses de la Unión que la que ofrecen a sus propios intereses.

37 Sobre las relaciones entre los principios de subsidiariedad y proporcionalidad, véase Donini (2003: 124 y ss.). 
completamente europeizado antes de la aprobación del Tratado de Lisboa a través de distintas decisiones marco (Picotti, 2006: 79).

El riesgo de que proliferaran las incriminaciones puso en alerta a un sector de la doctrina que firmó un «Manifiesto sobre la política criminal europea» como límite del nuevo derecho penal europeo que se veía venir, en el que se resaltaban los principios que han de legitimar el ius puniendi europeo: necesidad, ultima ratio, culpabilidad, legalidad (dentro del que se incluye el de determinación, la irretroactividad de las disposiciones penales o desfavorables así como la necesidad de una ley parlamentaria), subsidiariedad y coherencia (Asp, 2009; Tamarit Sumalla, 2009: 22).

A continuación se comprobará si las indicaciones de la UE en las materias a las que se refiere el art. 83.1 han vinculado a Reino Unido por su base normativa o por haber invocado el Protocolo 21. Solo entonces podrá calcularse el alcance de los efectos del brexit en el ámbito de la política criminal.

Con todo, como se decía anteriormente, esto no significa que las indicaciones penales de la Unión a los Estados miembros se limite a las materias a las que allí se hace referencia: basta comprobar la pluralidad de directivas aprobadas que han tenido la finalidad de vincular las legislaciones penales de los Estados miembros en otras parcelas de la criminalidad, entre las que podrían destacarse las siguientes: Directiva 2009/52/CE del Parlamento Europeo y del Consejo de 18 de junio de 2009 por la que se establecen normas mínimas sobre las sanciones y medidas aplicables a los empleadores de nacionales de terceros países en situación irregular ${ }^{38}$ (en virtud del art. 63 apdo. 3 letra b del TFUE); la Directiva 2011/92/UE del Parlamento Europeo y del Consejo, de 13 de diciembre de 2011, relativa a la lucha contra los abusos sexuales y la explotación sexual de menores y la pornografía infantil, por la que se sustituye la Decisión Marco 2004/68/JAI del Consejo (con base en los arts. 82.2 y $83.1)^{39}$, o la Directiva 2008/99/CE del Parlamento Europeo y del Consejo

38 DO L 168/24, de 30 de 6 de 2009 (p. 168).

39 DO L 335/1, de 17 de diciembre de 2011 (p. 1). Reino Unido no participa de la Directiva 2011/36/UE del Parlamento Europeo y del Consejo, de 5 abril de 2011, relativa a la prevención y lucha contra la trata de seres humanos y a la protección de las víctimas y por la que se sustituye la Decisión Marco 2002/629/JAI del Consejo (su art. 82, apdo. 2, y su art. 83, apdo. 1, del TFUE). El anexo de la Decisión de la Comisión de 1 de diciembre de 2014 relativa a la notificación por parte del Reino Unido e Irlanda del Norte de su deseo de participar en el ámbito de la cooperación policial y judicial en materia penal adoptados antes de la entrada en vigor del Tratado de Lisboa incluye la Decisión 2000/375/JAI del Consejo, de 29 de mayo de 2000, relativa a la lucha contra la pornografía infantil en internet (DO L 138, de 9 de junio de 2000 [p. 45]). 
de 19 de noviembre relativa a la protección del medio ambiente mediante el derecho penal ${ }^{40}$, basada en el art. 175 apartado 1 del TFUE.

Antes de pasar a analizar desde un punto de vista material si estas directivas han vinculado o no a Reino Unido, debe tenerse en consideración que hoy el art. 82.1 TFUE $^{41}$ establece, junto a la aproximación de las disposiciones legales de los Estados miembro — como consecuencia de la adopción de la misma política criminal de la UE en todos ellos-, la cooperación judicial y el reconocimiento mutuo de sentencias $^{42}$ : la consagración conjunta de ambos principios no tiene por qué entenderse necesariamente como subordinación de uno al otro, porque ciertamente puede hablarse de un reconocimiento mutuo de resoluciones judiciales adoptadas en base a leyes nacionales no idénticas. Ahora bien, como afirman Ambos y Bock (2017: 200), desde un punto de vista hermenéutico y sobre las materias a las que expresamente se refiere el párr. 2 del art. 83.1, la operatividad del reconocimiento mutuo de resoluciones es más lógica sobre legislaciones penales que se han aproximado previamente. Lo contrario, como afirman Ambos y Bock (2017: 200), «sería tanto como poner la carreta antes que los bueyes». Pues bien, a continuación podrá comprobarse cómo en una pluralidad de ocasiones la cooperación en materia procesal en las concretas materias mencionadas se produce al margen ya de la aproximación de las legislaciones penales.

\subsection{Delitos de terrorismo}

Que Reino Unido es uno de los grandes objetivos del terrorismo islamista parece innegable: basta comprobar la larga lista de atentados habidos en los últimos tiempos ${ }^{43}$. Y de que también lo es la UE tampoco cabe duda: las

40 Directiva 2011/36/UE del Parlamento Europeo y del Consejo, de 5 abril de 2011, relativa a la prevención y lucha contra la trata de seres humanos y a la protección de las víctimas y por la que se sustituye la Decisión Marco 2002/629/JAI del Consejo o la Directiva 2013/40/UE del Parlamento Europeo y del Consejo de 12 de agosto de 2013 DO L 328/28, de 6 de diciembre de 2008 (p. 47).

41 «La cooperación judicial en materia penal en la Unión se basará en el principio de reconocimiento mutuo de las sentencias y resoluciones judiciales e incluye la aproximación de las disposiciones legales y reglamentarias de los Estados miembros en los ámbitos mencionados en el apartado 2 y en el artículo 83».

42 Y ello con independencia de que ambos principios hayan llegado al acervo de la Unión Europea en distintos momentos: ahora interesa centrar la atención en el hecho de que después de esta trayectoria, el mismo artículo del TFUE los reconoce conjuntamente. Sobre esta cuestión véase Weyemberg (2004: 236-237).

43 https://elpais.com/internacional/2017/06/19/actualidad/1497867176_865461. html: fecha última consulta: 16 de octubre de 2017. 
estadísticas también lo confirman ${ }^{44}$. No está clara, sin embargo, la vinculación de la política de Reino Unido a la de la UE en contra del terrorismo.

En efecto, la Directiva (UE) 2017/54 del Parlamento Europeo y del Consejo de 15 de marzo de 2017, relativa a la lucha contra el terrorismo, por la que se sustituye la Decisión Marco 2002/475/JAI del Consejo y se modifica la Decisión 2005/671/JAI del Consejo ${ }^{45}$, con base en el art. 83 apdo. 1 TFUE (título V), califica al terrorismo como la forma más grave de atentar contra los valores universales de la dignidad humana, la libertad, la igualdad y la solidaridad, el respeto de los derechos humanos y las libertades fundamentales, sobre los que se fundamenta la propia UE, por lo que hay que deducir, de forma silogística, que el terrorismo constituye un atentado contra la propia UE (Acale Sánchez, 2007: 217 y ss.). Su considerando tercero justifica la existencia de la propia directiva en la necesidad «de una definición armonizada de los delitos de terrorismo» en todos los países de la UE, de referencia "para el intercambio de información y la cooperación entre las autoridades nacionales competentes». Por otra parte, se resalta la importancia de la coordinación de las distintas agencias de la UE —Eurojust y Europol_ para hacer frente a un fenómeno criminal que tiene un innegable carácter «transfronterizo». Y, en efecto, para luchar contra estos actos, es necesario que la propia directiva en la que se define el terrorismo, recurra a la Directiva (UE) 2015/849 del Parlamento Europeo y del Consejo en la que se establecen normas comunes relativas a la prevención de la utilización del sistema financiero de la Unión para el blanqueo de capitales o la financiación del terrorismo (con base en el art. 114 TFUE) $)^{46}$, en la medida en que una y otra tienen el mismo objetivo —la lucha contra el mismo fenómeno criminal—, aunque ponen su atención en aspectos distintos.

Pues bien, en el punto 41 de sus considerandos, la Directiva 2017/54 señala que Reino Unido, «de conformidad con los arts. 1 y 2 del Protocolo $21[\ldots]$ no participa(n) en la adopción de la presente Directiva y no queda(n) vinculado(s) por la misma ni sujeto(s) a su aplicación». Este hecho no puede evidenciar una disconformidad con la definición de delito de terrorismo, entre otros motivos porque con la aprobación de esta directiva la UE cumple los compromisos que mantiene con Naciones Unidas y con el Consejo de Europa, de los que también es miembro Reino Unido, sobre el cual, en paralelo,

44 https://politica.elpais.com/politica/2017/08/17/actualidad/1502997944_144229. html: fecha última consulta: 16 de octubre de 2017.

45

46 Véase infra. 
recaen las mismas obligaciones que recaen sobre la $\mathrm{UE}^{47}$. Particularmente con la Resolución 2178 (2014) del Consejo de Seguridad de Naciones Unidas por la que se expresó su preocupación ante la amenaza de los «combatientes terroristas extranjeros», solicitando a los Estados miembros que tipificasen esa conducta; y el Protocolo adicional del Convenio del Consejo de Europa para la prevención del terrorismo de 2015. Por tanto, el hecho de que Reino Unido no firme esta directiva no puede significar que defina el terrorismo de forma distinta.

Debe subrayarse que aunque el concepto de terrorismo no vincule a Reino Unido, Reino Unido no puede desvincularse de las acciones que se adopten para luchar contra este fenómeno criminal por parte de Europol y de Eurojust, para quienes la lucha contra el terrorismo es uno de sus objetivos fundamentales, con lo cual puede estar dándose la circunstancias denunciada por Ambos y por Bock, en virtud de la cual se antepone la cooperación procesal («el carro», en su ejemplo) a la penal («los caballos»). Por otra parte, la propia Directiva 2017/541 recurre a otras directivas que sí vinculan a Reino Unido, como la 2015/849 del Parlamento Europeo y del Consejo, de 20 de mayo de 2015, relativa a la prevención de la utilización de sistemas financieros para el blanqueo de capitales o la financiación del terrorismo ${ }^{48}$, que particularmente califica como «financiación del terrorismo» «el suministro o la recogida de fondos, por cualquier medio, de forma directa o indirecta, con la intención de utilizarlos o con el conocimiento de que serán utilizados, íntegramente o en parte, para la comisión de cualquiera de los delitos contemplados en la Decisión Marco 2002/475/JAI del Consejo».

Si a esto se le une el hecho de que a día de hoy es la misma clase de terrorismo la que azota al conjunto de la Unión Europa, que tiene dispersos por todo el territorio a «combatientes», que actúan dónde y cuándo se lo permiten los déficits de seguridad de los Estados miembros, que Reino Unido no haya

47 Esta es una de las excusas usadas por el legislador español para aprobar la Ley Orgánica 2/2015, de 30 de marzo, por la que se modifica la Ley Orgánica 10/1995, de 23 de noviembre, del Código Penal, en materia de delitos de terrorismo. Véase Terradillos Basoco (2016: 18 y ss.). Los efectos que el brexit desplegará en el ámbito de las relaciones internacionales y de los convenios y tratados internacionales suscritos por la Unión Europea antes del brexit se escapan a los estrictos contornos europeos y nacionales de este trabajo. Al respecto véase Escobar Fernández (2016: 19 y ss.).

Directiva 2011/36/UE del Parlamento Europeo y del Consejo, de 5 abril de 2011, relativa a la prevención y lucha contra la trata de seres humanos y a la protección de las víctimas y por la que se sustituye la Decisión Marco 2002/629/JAI del Consejo o la Directiva 2013/40/UE del Parlamento Europeo y del Consejo de 12 de agosto de 2013DO L 141, de 5 de junio de 2015 (p. 73). 
mostrado su intención de formar parte de la Directiva 2017/541 no tiene mucha explicación, ni desde el punto de vista de su fundamentación ni tampoco desde la perspectiva de su finalidad — la lucha contra un mismo fenómeno criminal-.

Con todo, la legislación antiterrorista de Reino Unido debe unirse a la línea político-criminal internacional y europea imperante (Walker, 2011: VI; 2014: 14). Así, la Anti-terrorism, Crime and Security Act de 2011 dedica su parte $13 \mathrm{al}$ «Third pillar of the European Union», en la que en esencia muestra su preocupación por los instrumentos procesales relativos a la extradición. A ella ha de añadirse la Terrorism Prevention and Investigation Measures Act de $2011^{49}$.

A la vista de todo esto, puede entenderse que el brexit, en materia de terrorismo, no va a suponer ningún cambio sustantivo y material para la legislación de Reino Unido, aunque a priori y como premisa sí supondrá un cambio importante en relación con el papel protagonista que hasta la fecha ha desarrollado en Eurojust y Europol: lo que no es poco ni para Reino Unido ni tampoco para la UE, que se deja en el camino a uno de los Estados más entusiastas en la lucha contra el delito en el mapa de la Unión. Todo ello obviamente con independencia de que ex post - brexit-, Reino Unido llegue a firmar acuerdos que garanticen su participación en ambas agencias.

\subsection{Delitos de blanqueo de capitales y falsificación de medios de pago}

La Directiva 2015/849 del Parlamento Europeo y del Consejo, de 20 de marzo de 2015, relativa a la prevención de la utilización del sistema financiero para el blanqueo de capitales y la financiación del terrorismo ${ }^{50}$, y por la que se modifica el Reglamento (UE) 648/2012 del Parlamento Europeo y del Consejo, y se derogan la Directiva 2005/60/CE del Parlamento Europeo y del Consejo y la Directiva 2006/70/CE de la Comisión (con base en el art. 114 TFUE, del capítulo 3 del título VII) se dirige a «los Estados miembros» sin excepción, entre ellos Reino Unido, que quedó por tanto vinculado por sus indicaciones, a pesar del contenido estrictamente penal de todo su articulado. En este sentido, por la fecha de la directiva -20 de marzo de 2015 - y por la fecha del referéndum del brexit — 23 de junio de 2015- Reino Unido se encontró con una situación comprometida porque, si bien se preparaba para su salida de la UE, tuvo que aprobar la Money

49 Que deroga a su vez la Prevention of Terrorism Act 2005.

50 DO L 141, de 5 de junio de 2015 (p. 73). 
Laundering and Transfer of Funds (Information on the Payer) Regulation de 2017, de transposición de la cuarta Directiva de blanqueo de capitales y financiación del terrorismo a la que aquí se hace referencia, que entró en vigor el 26 de junio de $2016^{51}$.

Cabe plantearse qué ocurrirá cuando las negociaciones del brexit culminen y, de hecho, Reino Unido abandone la UE, porque o bien se convalida la Statutory Instruments núm. 692, 2017, olvidándose de que en su génesis se aprobó para hacer frente a la necesidad de ratificación de una directiva, o aprueba una nueva Statutory sobre el lavado de activos en Reino Unido, tenga el dinero blanqueado el origen que tenga. En cualquier caso, hay que pensar que mientras tanto las rules judiciales no tienen por qué cambiar, pues aunque desaparezca el formato papel de la ley, hasta donde tenga permitido la jurisprudencia, podrá seguir castigando los «delitos» de blanqueo de capitales y de financiación del terrorismo ${ }^{52}$.

\subsection{Delitos de corrupción pública, fraude de los intereses financieros de la Unión y delincuencia organizada}

La Directiva (UE) 2017/1371 del Parlamento Europeo y del Consejo de 5 de julio de 2017 sobre la lucha contra el fraude que afecta a los intereses financieros de la Unión a través del derecho penal ${ }^{53}$, con base en lo dispuesto en el art. 83 apdo. 2 del TFUE, viene a sustituir al Convenio relativo a la protección de los intereses financieros de las Comunidades Europeas de 26 de julio de $1995^{54}$ (en cuya exposición de motivos se puso de manifiesto la necesidad «de adaptar — vía asimilación — las legislaciones nacionales en la medida en que no tipifiquen como delito los actos de corrupción que causen o puedan causar perjuicio a los intereses financieros de las Comunidades Europeas y en los que estén implicados funcionarios comunitarios o funcionarios de otros Estados miembros»), así como sus tres protocolos ${ }^{55}$.

51 Statutory Instruments núm. 692, 2017.

52 Un análisis sobre la forma de luchar a nivel internacional y europeo contra la delincuencia organizada y el blanqueo de capitales puede verse en Faraldo Cabana (2014: 13 y ss.).

53 DO L 198, de 28 de julio de 2017 (p. 29).

54 DO C 151, de 20 de mayo de 1997 (p. 1). En su art. 6 contiene las reglas de aplicación de las respectivas leyes penales nacionales en el espacio; véase Nieto Martín (1998: 225-226) y (1996: 5 y ss.). Sobre el concepto de «corrupción», véase también Nieto Marín (2006).

55 Imprescindible la lectura de Terradillos Basoco (2015: 15 y ss.). 
Su contenido es amplio, pues abarca no solo las medidas que puedan afectar a los intereses de la Unión, sino también las referidas a los intereses de los Estados miembros si guardan relación con las políticas de aquella; desde esta perspectiva se entiende pues la apuesta por seguir armonizando las legislaciones de los Estados miembros en esta materia ${ }^{56}$. En su interior se hace mención a las concretas conductas materiales constitutivas de fraude de impuestos (IVA) y de cohecho activo y pasivo, y además compromete a los Estados a castigar el blanqueo de estos capitales.

La legitimidad de la UE para dar a los Estados miembros indicaciones precisas para que procedan a tutelar sus intereses financieros parece innegable, más allá incluso de lo dispuesto en el título V TFUE, en la medida en que el art. 325 establece que la Unión y los Estados miembros «combatirán el fraude y toda actividad ilegal que afecte a los intereses financieros de la Unión mediante medidas adoptadas en virtud de lo dispuesto en el presente artículo, que deberán tener un efecto simbólico y ser capaces de ofrecer una protección eficaz en los Estados miembros en las instituciones y organismos de la Unión».

Sin embargo, a pesar de la relevancia de los intereses económicos para la UE, según dispone el considerando 37 de la directiva, «el Reino Unido no participa en la adopción de la presente Directiva y no queda vinculado por la misma ni sujeto a su aplicación». En su decisión probablemente haya incidido de forma considerable la fecha de la directiva y la vorágine de los trabajos preparatorios de la salida de Reino Unido de la UE, que han determinado que la protección de los intereses financieros de la Unión no represente para Reino Unido un problema con mucho recorrido. Esto no significa que no venga obligado a velar por los intereses financieros de la UE; tampoco que no tenga que perseguir estas infracciones: significa que, según señala su art. 16, en relación con Reino Unido sigue estando en vigor el Convenio relativo a la protección de los intereses financieros de las Comunidades Europeas de 26 de julio de $1995^{57}$. Por todo esto, Reino Unido debe actuar con la misma

56 Línea ya abierta con el Reglamento (CE, Euratom) 2988/95.

57 La compleja situación que se produce en torno al derecho de la Unión Europea aplicable en materia de protección de los intereses financieros de la Unión Europea en Reino Unido se acrecienta cuando se comprueban las referencias que se hacen en la Directiva 2017/1371 en su art. 15 a la cooperación entre los Estados miembros y a la Comisión (Olaf) y a otras instituciones, órganos u organismos de la Unión, entre ellos Eurojust, de la cual sí participa Reino Unido. Es decir, de nuevo se constata que la cooperación procesal va más avanzada que la relativa al derecho penal sustantivo: en otras palabras, poco sentido tiene que Reino Unido procure facilitar las operaciones policiales y judiciales de lucha contra el fraude de los intereses financieros de la Unión Europea, si 
diligencia con la que actúa para proteger sus intereses, cuando se trate de conductas que afecten a los intereses financieros de la UE, como ya dejara sentado hace años la Sentencia del Tribunal de Justicia de la Comunidad Europea de 21 de septiembre de 1989 (caso del maíz griego ${ }^{58}$ ), cuya jurisprudencia también vincula a los Estados miembros. Esto hace necesario recurrir a la Bribery Act de 2010 — calificada como una de las leyes más duras del mundo contra la corrupción (Monty, 2016: 225)—, que aprobó Reino Unido con la finalidad de cumplir con las disposiciones del Convenio de la OCDE de $1997^{59}$. En este sentido es interesante resaltar que la preocupación científica específica que plantea la persecución del fraude a los intereses financieros de la UE en Reino Unido, una vez situado el marco normativo en el ámbito del Convenio de 1995 y de sus tres protocolos (Monty, 2016: 225 y ss.), sea lo relativo a la aplicación de la extradición y la orden de detención (Pieth, 2007: 415), preocupaciones que, como se señalaba anteriormente, también se ponían sobre la mesa en el ámbito de la nueva Directiva 2017/54 relativa al terrorismo, tampoco adoptada ni aplicada por Reino Unido $^{60}$.

La salida definitiva de Reino Unido de la UE hará que deje de ser un problema para este país el fraude de subvenciones a un presupuesto del que ya no será parte y del que ya no se beneficiará la población inglesa. Tampoco podrán defraudarse impuestos que no deberán pagarse, porque, en efecto, como ha afirmado la doctrina que originariamente se ocupó de analizar el nacimiento del derecho penal comunitario, la protección de los intereses financieros de la UE es un genuino bien jurídico europeo, por lo que abandonada la Unión — premisa mayor - dejará de prestar atención a la protección de uno de sus intereses — premisa menor- (Tiedemann, 1999: 655; Verbaele, 1992).

Ahora bien, criminológicamente deberá someterse a observación si los cambios políticos que el brexit traerá consigo ${ }^{61}$ se convertirán en factores de precipitación de procesos de corrupción propios, específicos y funcionales al momento político que la genera: por todo ello, será interesante observar si la salida se produce relajando los estándares anticorrupción de la UE o no.

no acepta el instrumento en el que se señalan cuáles son las concretas conductas que deben castigarse en cada uno de los ordenamientos jurídicos de los Estados miembros. Véase Ambos y Bock (2017: 200).

58 Disponible en: https://goo.gl/bdyayd (fecha de la última consulta: 23-10-2017). Véase Acale Sánchez (2001: 43 y ss.).

59 Véase ampliamente el trabajo coordinado por Pieth (2007).

60 Véase supra.

61 En Reino Unido, en la Unión Europea y para cada uno de los Estados miembros de la Unión Europea. 


\subsection{Delitos informáticos}

La Directiva 2013/40/UE del Parlamento Europeo y del Consejo de 12 de agosto de 2013 relativa a los ataques contra los sistemas de información y por la que se sustituye la Decisión Marco 2005/222/JAI ${ }^{62}$, en virtud de lo establecido en el art. 83.1 TFUE, contiene indicaciones precisas sobre conductas constitutivas de delito, las sanciones a imponer, así como sobre la obligación que tienen los Estados a efectos del intercambio de información de «uso de red existente de puntos de contactos operativos disponible 24 horas al día, siete días a la semana», poniendo con ello de manifiesto la necesidad de coordinación interestatal para luchar contra una clase de delincuencia que no tiene que desplazarse físicamente para la comisión de sus delitos, aunque los resultados de sus actividades pueden alcanzar cualquier lugar del planeta $^{63}$.

Pues bien, en atención a lo dispuesto en el considerando 31, Reino Unido notificó su deseo de participar en la adopción y aplicación de esa directiva y ha dado lugar a la aprobación de la Statutory Instruments Criminal Justice (Offences relating to information systems) Act, núm. 11 de 2017. Tras la salida de Reino Unido de la UE, de nuevo, esta normativa dejará de tener como base la necesidad de cumplir con un compromiso de la UE, y Reino Unido deberá plantearse si aprueba una nueva o si haciendo abstracción de su origen la convalida como derecho interno.

No cabe duda de que el brexit va a suponer que Reino Unido se enfrente de forma autónoma a esta clase de delincuencia, pero carece completamente de sentido que lo haga de forma independiente, porque el fenómeno criminal está «organizado» a lo largo de todos los Estados miembros.

62 DO L 218, de 14 de agosto de 2013 (p. 8).

63 La lucha contra la delincuencia informática es uno de los objetivos centrales de la Unión Europea. En este sentido, al margen ya de la Directiva 2013/40/UE, puede verse el Informe de 26 de julio de 2017 de la Comisión de Libertades Civiles, Justicia y Asuntos de Interior sobre la lucha contra la ciberdelincuencia (2017/2068 (INI)), disponible en: https://goo.gl/FLMGiH (fecha de la última consulta: 1012018). También puede verse la Directiva (UE) 2016/681 del Parlamento Europeo y del Consejo de 27 de abril de 2016 relativa a la utilización de datos del registro de nombres de pasajeros (PNR) para la prevención, detección, investigación y enjuiciamiento de los delitos de terrorismo y de la delincuencia grave, que considera los delitos informáticos dentro del anexo II como uno de los delitos graves que dan lugar a la aplicación de la directiva. Reino Unido, en aplicación del Protocolo 21, según dispone la directiva en su punto 39, manifestó su deseo de participar en la adopción y aplicación de la misma. 


\section{APROXIMACIÓN A LOS ASUNTOS RELATIVOS A LA COOPERACIÓN EN MATERIA PROCESAL}

\section{PRINCIPIO DE RECONOCIMIENTO MUTUO DE RESOLUCIONES JUDICIALES}

Desde que se celebrara en Tampere en octubre de 1999 la reunión del Consejo de Ministros de Justicia e Interior, y se acordara la necesidad de eliminar las «trabas» procesales derivadas del procedimiento de extradición, en el marco instaurado por el Tratado de Ámsterdam, que en lo que aquí interesa creara el espacio de libertad, seguridad y justicia, y que se diera prioridad al principio de reconocimiento mutuo de las decisiones judiciales adoptadas entre los distintos Estados miembros, se han sucedido en el tiempo distintas decisiones marcos y directivas que no han venido más que a concretar los puntos de partida que allí se dejaron sentados ${ }^{64}$.

Han sido varios los pronunciamientos en el ámbito del derecho europeo en materia de la ejecución de sanciones penales, en virtud del principio de reconocimiento mutuo ${ }^{65}$. En particular, han de resaltarse la Decisión Marco 2002/584/JAI relativa a la orden europea y a los procedimientos de entrega entre Estados miembro ${ }^{66}$; la Decisión Marco 2003/577/JAI de 22 de julio de 2003, relativa a la ejecución de resoluciones de embargo preventivo de bienes y aseguramiento de pruebas ${ }^{67}$; la Decisión Marco 2005/214/JAI del Consejo, de 24 de febrero de 2005 , relativa a la aplicación del principio de reconocimiento mutuo de sanciones pecuniarias ${ }^{68}$; la Decisión Marco 2006/783/JAI

64 Sobre la cooperación en el ámbito procesal, véase Mesko (2017: 109-121).

65 La proliferación normativa de la Unión Europea en este sentido ha sido tal que el legislador español, como declara en el preámbulo de la Ley 23/2014, de 20 de noviembre, de reconocimiento mutuo de resoluciones penales en la Unión Europea, «da por amortizada la técnica de la incorporación individual de cada decisión marco o directiva europea en una ley ordinaria y su correspondiente ley orgánica complementaria, y se presenta como un texto conjunto en el que se reúnen todas las decisiones marco y la directiva aprobadas hasta hoy en materia de reconocimiento mutuo de resoluciones penales. Incluye tanto las ya transpuestas a nuestro Derecho como las que están pendientes, evitando la señalada dispersión normativa y facilitando su conocimiento y manejo por los profesionales del Derecho. Además, se articula a través de un esquema en el que tiene fácil cabida la incorporación de las futuras directivas que puedan ir adoptándose en esta materia».

66 DO L 190, de 18 de julio de 2002 (p. 1).

67 DO L 196, de 2 de agosto de 2003 (p. 45).

68 Incluida en el anexo de la Decisión de la Comisión de 1 de diciembre de 2014 relativa a la notificación por parte del Reino Unido e Irlanda del Norte de su deseo de partici- 
del Consejo, de 6 de octubre de 2006, relativa a la aplicación del principio de reconocimiento mutuo de resoluciones de decomiso ${ }^{69}$; la Decisión Marco 2007/8445/JAI del Consejo de 6 de diciembre de 2007 sobre cooperación entre los órganos de recuperación de activos de los Estados miembros en el ámbito del seguimiento y la identificación de productos del delito o de otros bienes relacionados con el delito ${ }^{70}$; la Decisión Marco 2008/909/JAI del Consejo, de 27 de noviembre de 2008, relativa a la aplicación del principio de reconocimiento mutuo de sentencias en materia penal por las que se imponen penas u otras medidas privativas de libertad a efectos de su ejecución en la UE ${ }^{71}$; la Decisión Marco 2008/947/JAI del Consejo de 27 de noviembre de 2008, relativa a la aplicación del principio de reconocimiento mutuo de sentencias y resoluciones de libertad vigilada con miras a la vigilancia de las medidas de libertad vigilada y las penas sustitutivas ${ }^{72}$; la Decisión Marco 2009/299/JAI, del Consejo, de 26 de febrero de 2009 por la que se modifican las Decisiones Marco 2002/584/JAI, 2005/214/JAI, 2006/909/JAI y 2008/847/JAI, destinada a reforzar los derechos procesales de las personas y a propiciar la aplicación del reconocimiento mutuo de las resoluciones dictadas a raíz de juicios celebrados sin comparecencia del imputado ${ }^{73}$; la Decisión

par en el ámbito de la cooperación policial y judicial en materia penal adoptados antes de la entrada en vigor del Tratado de Lisboa.

69 DO L 328, de 24 de noviembre de 2006 (p. 59). Incluida en el anexo de la Decisión de la Comisión de 1 de diciembre de 2014 relativa a la notificación por parte del Reino Unido e Irlanda del Norte de su deseo de participar en el ámbito de la cooperación policial y judicial en materia penal adoptados antes de la entrada en vigor del Tratado de Lisboa. Véase Rodríguez Puerta (2009, 399 y ss.).

70 DO L 332, de 18 de diciembre de 2007 (p. 103).

71 DO L 327, de 5 de diciembre de 2008 (p. 27). Incluida en el anexo de la Decisión de la Comisión de 1 de diciembre de 2014 relativa a la notificación por parte del Reino Unido e Irlanda del Norte de su deseo de participar en el ámbito de la cooperación policial y judicial en materia penal adoptados antes de la entrada en vigor del Tratado de Lisboa.

72 DO L 337, de 16 de diciembre de 2008 (p. 102).

73 DO L 81, de 27 de marzo de 2009 (p. 24). Su objetivo no es otro que cubrir un vacío existente en las anteriores decisiones marcos en relación con las resoluciones dictadas a raíz de juicios celebrados sin comparecencia del imputado, señalando que «esta diversidad de planteamientos podría complicar la labor de los profesionales y dificultar la cooperación judicial». Incluida dentro del anexo de la Decisión de la Comisión de 1 de diciembre de 2014 relativa a la notificación por parte del Reino Unido e Irlanda del Norte de su deseo de participar en el ámbito de la cooperación policial y judicial en materia penal adoptados antes de la entrada en vigor del Tratado de Lisboa. 
Marco 2009/829/JAI, de 23 de octubre de 2009, relativa a la aplicación del principio de reconocimiento mutuo a las resoluciones sobre medidas de vigilancia como sustitución de la prisión provisional ${ }^{74}$; la Directiva 2011/99/UE, de 13 de diciembre de 2011, sobre la orden europea de protección ${ }^{75}$; así como la Directiva 2014/41/CE del Parlamento Europeo y del Consejo, de 3 de abril de 2014, relativa a la orden europea de investigación en materia penal (que facilita la práctica de las pruebas). En esta misma línea de medidas que permiten el reconocimiento mutuo de resoluciones judiciales deben tenerse también en cuenta la Decisión Marco 2008/675/JAI del Consejo, de 24 de julio de 2008, relativa a la consideración de las resoluciones condenatorias entre los Estados miembros de la UE con motivo de un nuevo proceso penal ${ }^{76}$, y la Decisión Marco 2008/315/JAI, de 26 de febrero de 2009, relativa a la organización y al contenido del intercambio de información de los registros de antecedentes penales entre Estados miembros ${ }^{77}$.

Todos estos instrumentos de la Unión han favorecido la confianza mutua entre los distintos Estados miembros que actúan en materia de prevención de la delincuencia y de ejecución de sanciones penales con un apoyo recíproco.

Pues bien, si a priori se plantea qué significado tiene el brexit en el ámbito de la cooperación procesal, y con independencia de que a posteriori Reino Unido esté interesado en mantener un estatuto específico con la Unión y con los países miembros de ella, el brexit supone desde un punto de vista lógico-teórico en puridad de principios que Reino Unido dejará de reconocer

74 DO L 294, de 11 de noviembre de 2009 (p. 20). Incluida en el anexo de la Decisión de la Comisión de 1 de diciembre de 2014 relativa a la notificación por parte del Reino Unido e Irlanda del Norte de su deseo de participar en el ámbito de la cooperación policial y judicial en materia penal adoptados antes de la entrada en vigor del Tratado de Lisboa.

75 A todas ellas se hace referencia en el preámbulo de la Ley 23/2014, de 20 de noviembre, de reconocimiento mutuo de resoluciones penales en la Unión Europea.

76 Incluida dentro del anexo de la Decisión de la Comisión de 1 de diciembre de 2014 relativa a la notificación por parte del Reino Unido e Irlanda del Norte de su deseo de participar en el ámbito de la cooperación policial y judicial en materia penal adoptados antes de la entrada en vigor del Tratado de Lisboa. También se incluye la Decisión Marco 2009/315/JAI del Consejo, de 26 de febrero de 2009, relativa a la organización y al contenido del intercambio de información de los registros de antecedentes penales entre los Estados miembros (DO L 93, de 7 de abril de 2009, p. 33).

77 Incluida en el anexo de la Decisión de la Comisión de 1 de diciembre de 2014 relativa a la notificación por parte del Reino Unido e Irlanda del Norte de su deseo de participar en el ámbito de la cooperación policial y judicial en materia penal adoptados antes de la entrada en vigor del Tratado de Lisboa. 
las resoluciones judiciales dictadas por los países de la UE, los cuales, recíprocamente, dejarán de reconocer las suyas. Con los resultados de esta decisión, se produce un retroceso de dieciocho años, pues volverá a la senda seguida antes del Consejo de Ministros de Tampere, ralentizando la persecución policial de los delincuentes que convierten el mapa de la UE en su refugio y el reconocimiento de las resoluciones judiciales adoptadas en el resto de países de la Unión.

En este sentido, la pregunta que verdaderamente debe plantearse en estos momentos es la siguiente: ¿qué efectos positivos genera para Reino Unido no reconocer ab initio las decisiones judiciales de los países miembros de la UE y que además sus resoluciones judiciales no sean reconocidas en el resto de esos países? Por ejemplo, si se piensa en la orden europea de detención, instrumento veloz para luchar contra la delincuencia, de no reconocerse las resoluciones judiciales dictadas por otros países habrá que recurrir tanto por Reino Unido como por los países miembros de la Unión que quieran que se proceda a la detención de una persona que se encuentre en Reino Unido a la extradición (Leonard, 2017: 9; Weyemberg, 2017: 295), mucho más garantista, eso sí, que la orden de detención ${ }^{78}$, que prescinde para un determinado grupo de delitos de principios básicos como el de doble incriminación, o la entrega de los nacionales (Weyembergh, 2017: 295) ${ }^{79}$. Lo que tiene todo su sentido, pues con el brexit, Reino Unido ha demostrado que deja de confiar en los países miembros de la UE y en la propia UE: esto es el brexit, una pérdida de confianza (Jimeno-Bulnes, 2017: 339). La lógica nos debería ayudar a comprender el resultado producido, y si no es así, es que algo ha fallado: en este sentido, de «la pérdida de confianza en la UE» (premisa mayor), debería desprenderse con comodidad la "pérdida de confianza en la orden de detención europea» (premisa menor). Ahora bien, a la vista de las posibilidades —reales - existentes de que Reino Unido alcance un acuerdo con la UE para

78 Anexo de la Decisión de la Comisión de 1 de diciembre de 2014 relativa a la notificación por parte del Reino Unido e Irlanda del Norte de su deseo de participar en el ámbito de la cooperación policial y judicial en materia penal adoptados antes de la entrada en vigor del Tratado de Lisboa, que incluye la Decisión Marco 2002/584/ JAI del Consejo, de 13 de junio de 2002, relativa a la orden de detención europea y a los procedimientos de entrega entre Estados miembros (DO L 190, de 18 de julio de 2002 (p. 1)).

79 Ya en 2008 afirmaba Jimeno-Bulnes (2008: 26) que en vez de eliminar el requisito de la doble incriminación, "podrían haberse adoptado en el texto europeo otras soluciones menos 'agresivas' al menos con carácter inicial por lo que respecta a esta exigencia (o no) de la doble incriminación, como principio clásico hasta ahora en el llamado auxilio judicial internacional». 
mantener en vigor el reconocimiento mutuo de resoluciones judiciales o la orden de detención europea, como se ha puesto de manifiesto en el Parlamento de Reino Unido desde el inicio de las negociaciones (y a ello apuntaba Teresa May en la carta de desconexión), parece que el silogismo planteado carece de lógica. Por tanto, el abandono de la UE se produce por otras razones, no porque los vínculos existentes en materia procesal penal se hayan mostrado ineficaces.

\section{ORGANISMOS PROPIOS DE LA UE PARA LUCHAR CONTRA EL DELITO}

La cooperación y coordinación entre los Estados miembros y entre autoridades policiales y judiciales es básica para que el espacio de libertad, seguridad y justicia sea una realidad. En este sentido, deben resaltarse los esfuerzos de la Unión dirigidos a la puesta en marcha de mecanismos de este tipo.

Así, si en el marco sustantivo se ha hecho referencia a la importancia de la lucha contra el fraude a los intereses financieros de la UE, desde el punto de vista procesal debe tenerse en consideración la Olaf, la Oficina europea de lucha contra el fraude, creada en 1999 por la Decisión de la Comisión $1999 / 352 / \mathrm{EC}^{80}$, que a pesar de su naturaleza administrativa y de sus funciones preventivas del fraude puede llevar a cabo medidas de investigación de carácter coercitivo (Ambos y Bock, 2017: 211).

En el ámbito de la cooperación judicial específica, debe resaltarse el papel que juega Eurojust (art. 85 TFUE), creada por la Decisión del Consejo 2002/187/JAI ${ }^{81}$, cuya función es la de «apoyar y reforzar la coordinación y la cooperación entre las autoridades nacionales encargadas de investigar y perseguir la delincuencia grave que afecte a dos o más Estados miembros o que deba perseguirse según criterios comunes, basándose en las operaciones efectuadas y en la información proporcionada por la autoridades de los

80 DO L 136, de 31 de mayo de 1999 (p. 25).

81 DO 063, de 6 de marzo de 2002 (p. 63). Incluida en el anexo de la Decisión de la Comisión de 1 de diciembre de 2014 relativa a la notificación por parte del Reino Unido e Irlanda del Norte de su deseo de participar en el ámbito de la cooperación policial y judicial en materia penal adoptados antes de la entrada en vigor del Tratado de Lisboa. También incluye la Decisión 2003/659/JAI del Consejo, de 18 de junio de 2003, por la que se modifica la Decisión 2002/187/JAI por la que se crea Eurojust para reforzar la lucha contra las formas graves de delincuencia (DO, L. 245, 29.9.2003), así como la Decisión 2009/426/JAI del Consejo, de 16 de diciembre de 2008, por la que se refuerza Eurojust y se modifica la Decisión 2002/187/JAI por la que se crea Eurojust para reforzar la lucha contra las formas graves de delincuencia (DO L138, de 4 de junio de 2009 [p. 14]). 
Estados miembros y por Europol»; posteriormente sus previsiones fueron desarrolladas por la Decisión del Consejo 2009/426/JAI, relativa al fortalecimiento de Eurojust y por la que se modifica la Decisión 2002/187/JAI por la que se crea Eurojust, con objeto de reforzar la lucha contra la delincuencia grave $^{82}$. Su nacimiento tuvo lugar una vez que la UE constató la necesidad de cruzar fronteras en la lucha contra el delito también por parte de las autoridades judiciales (Ambos y Bock, 2017: 213).

Por otra parte, el art. 86 del TFUE previó la creación de una Fiscalía Europea a partir de Eurojust "para combatir las infracciones que perjudiquen los intereses financieros de la Unión». Como recuerda Mitsilegas (2017a: 221; 2016: 103 y ss.), Reino Unido ha usado la facultad que le confiere el Protocolo 21 para no firmar el Tratado por el que se establece el Ministerio Público Europeo y, sin embargo, sí firmó la Directiva de la Orden de Investigación Europea en materias penales. En su opinión, «la selectiva participación de Reino Unido en este contexto es problemática no solo desde la perspectiva de la protección de los derechos fundamentales, sino también desde la perspectiva de la coherencia del derecho de la UE». Como puede observarse, en este caso, y siguiendo el ejemplo de Ambos y de Bock al que se ha hecho referencia con anterioridad, no se trataría ya de poner antes la «carreta» (el derecho procesal) que los bueyes (el derecho penal), sino solo una parte de aquella.

El principio de cooperación policial se reconoce en el art. 87 TFUE. En el art. 88 TFUE se afirma que «la función de Europol es apoyar y reforzar la actuación de las autoridades policiales y de los demás servicios con funciones coercitivas de los Estados miembros, así como su colaboración mutua en la prevención de la delincuencia grave que afecte a dos o más Estados miembros, del terrorismo y de las formas de delincuencia que lesionen un interés común que sea objeto de una política de la Unión, así como en la lucha en contra de ellos». Es la Decisión del Consejo 2009/371/JAI la que establece la Oficina policial europea (Europol) (Mitsilegas, 2017a: 221; 2016: 103 y ss.). Su importancia en la lucha policial coordinada en el seno de la UE contra el delito resulta difícilmente discutible, realizando tareas de investigación, depósito, procesamiento, análisis e intercambio de información (Ambos y Bock, 2017: 212).

En esta sede tampoco deben ser olvidados los magistrados y los fiscales que conforman la red judicial europea ${ }^{83}$, cuya actuación es relevante en el seno de la orden europea de detención. Por otra parte, como recuerda Jimeno-Bulnes, España ha mantenido magistrados de enlace con Reino Unido,

82 DO L 138, de 4 junio de 2009 (p. 14).

83 Para más información véase Ambos y Bock (2017: 213). 
así como con otros países que a pesar de no ser miembros de la UE, como Marruecos o Estados Unidos, se han considerado de interés en virtud de tratados internacionales y acuerdos bilaterales, en los que confía ahora para el mantenimiento del magistrado de enlace entre España y Reino Unido (Jimeno-Bulnes, 2017: 332; Leonard, 2017: 8).

Comparativamente, si los efectos del brexit en materia penal pueden ser más limitados debido a las especiales características de la integración de Reino Unido en la UE, desde un punto de vista procesal y policial sí van a tener un mayor calado, pues la salida conlleva a priori - y con independencia de los acuerdos puntuales que se alcancen — simultáneamente la salida de la Olaf, de Interpol y de Eurojust, instituciones desde las cuales se lucha contra la delincuencia en el ámbito de la UE y en cuyo funcionamiento Reino Unido ha mostrado un compromiso y una responsabilidad considerables (Jimeno-Bulnes, 2017: 329). Y ello puede significar que se dificulte la persecución ordenada de fenómenos criminales organizados a todo lo largo y ancho de Europa y para los que muchas veces el concreto lugar en el que se cometen sus delitos es mera consecuencia de simples déficits de seguridad ${ }^{84}$ : basta pensar, como se afirmaba anteriormente, en los últimos delitos de terrorismo. Por ello, por el lado de la delincuencia, Reino Unido corre el riesgo de convertirse en un paraíso de criminales que domicilien sus actividades económicas en su suelo (Jimeno-Bulnes, 2017: 329), a fin de evitar los controles de todo el aparataje procesal europeo.

Por ello, y en definitiva, a priori el brexit puede causar un efecto boomerang en materia penal para Reino Unido porque con el referéndum el pueblo de Reino Unido ha puesto de manifiesto su voluntad de salir de la UE y, en términos generales, lo que ella conlleva, que en materia procesal se condensa en una serie de institutos como Olaf, Interpool o Eurojust, que pretenden la lucha ordenada y eficaz contra el delito: si a esto se le une la teórica renuncia al reconocimiento mutuo de resoluciones judiciales, y la vuelta a los instrumentos de extradición, que son instituciones que frenan la comisión de delitos, el efecto que se alcance puede ser el de generar más delincuencia, al tiempo que impida que en la UE se controle como hasta este momento.

Curiosamente, aquel sector de la sociedad de Reino Unido optimista con las puertas que se cierran a la mano de obra extranjera comparte preferencias

84 Recuerda en este sentido Bock (2017: 312) cómo, tras el atentado del 16 de diciembre de 2016 en el mercado de Berlín, reivindicado por el ISIS y en el que doce personas fueron asesinadas y cuarenta resultaron heridas, las autoridades alemanas llevaron a cabo una persecución del principal sospechoso a través de Holanda, Bélgica, Francia y finalmente Italia, donde este resultó muerto por la Policía italiana. 
con las organizaciones criminales, que también consideran el brexit una oportunidad para el desarrollo de sus actividades delictivas.

Con el fin de evitar el efecto criminógeno señalado, la doctrina especializada viene a coincidir con Child y Ormerod (2017: 20) en el hecho de que en pro del desarrollo de las políticas preventivas de la criminalidad de la UE, los pasos dados en materia de cooperación penal y procesal no se desanden después del brexit y se acuerde alguna manera mantener esta vinculación ${ }^{85}$ : es más, el brexit es una oportunidad única hasta la fecha para comprobar si los canales de cooperación procesal entre las agencias, la UE y los Estados miembros son capaces de mantenerse después de él, lo que pondría de manifiesto la independencia alcanzada por ellos (Mitsilegas, 2017a: 240).

\section{EL LIMITADO CONTENIDO ESTRICTAMENTE PENAL DE LOS ACUERDOS PREVIOS AL TRATADO DE DESCONEXIÓN}

Como ha podido comprobarse, los asuntos penales que deben atenderse en este proceso de salida emprendido por Reino Unido de la UE no son pocos ni insignificantes, y, sin embargo, a la vista del contenido de los acuerdos o intentos de acuerdos habidos hasta la fecha entre los representantes de uno y otro en los grupos de trabajo que intenta cerrar el brexit, negociándolo, poco peso han tenido (están teniendo) en las negociaciones, centradas y preocupadas en la libre circulación de personas por el territorio de la UE y en dar seguridad a las empresas y a la economía. Hay que tener en cuenta que Reino Unido es un país en el que residen muchos ciudadanos de países miembros para los cuales el brexit va a llevar aparejadas consecuencias relevantes en materia laboral, de residencia y de derecho de familia. Pero también, como recordaba Theresa May en su misiva, hay muchos ciudadanos de Reino Unido residiendo fuera de la Unión: el principio de reciprocidad será el que rija el tratamiento de los ciudadanos de Reino Unido y de la $\mathrm{UE}^{86}$. Ahora bien, la importancia de esto último no justifica que se hayan obviado los aspectos de naturaleza jurídico penal o que se le haya prestado la escasa atención que trasluce la lectura de los acuerdos en la primera fase de las negociaciones ${ }^{87}$.

85 Resalta Weyembergh (2017: 292) que «se corre el riesgo de reducir la efectividad en la lucha contra el crimen transnacional y los beneficios del delito».

86 TF50 (2017) 1 Commission to EU27, de 24 mayo; TF50 (2017) 16 Commission to EU 27, de 31 de agosto.

87 Centrar la atención en los puntos de los acuerdos en los que expresamente se hace mención a los aspectos penales no impide reconocer que hay otros temas en los que, 
En efecto, el documento sobre "Cooperación judicial y policial en materias penales» se dirige al resto de países de la UE y se firmó el 28 de junio ${ }^{88}$; el 12 de julio se da traslado del mismo a Reino Unido ${ }^{89}$. De su contenido se desprende que la preocupación en este primer documento de las negociaciones ha sido más procesal-penal que penal. Así, y dada la complejidad de las materias a tratar y al propio proceso de desconexión, se establece que el acuerdo de retirada debe permitir el cumplimiento ordenado de los procedimientos en curso basados en la orden de investigación europea (Directiva 2014/41/EU ${ }^{90}$ ), la orden de arresto europeo (Decisión Marco del Consejo 2002/584/JHA ${ }^{91}$ ), el reconocimiento de órdenes de decomiso (Decisión Marco 2006/78392), el mutuo reconocimiento de sanciones económicas (Decisión Marco 2005/214/JAI ${ }^{93}$ ), el reconocimiento de penas de prisión - circulación de prisioneros- (Decisión Marco 2008/909/JAI $\left.{ }^{94}\right)$, la asistencia mutua y cooperación entre administraciones aduaneras (Acta del Consejo de 18 de diciembre de 1997-Nápoles II ${ }^{95}$ ), ECRIS (Decisión Marco del Consejo 2009/315/JAI y 2009/316/JAI ${ }^{96}$ ), la orden europea de protección (Directiva 2011/99/EU97); el requerimiento de información o datos según las autoridades policiales (Decisión Marco 2006/960/JAI ${ }^{98}$ ); el registro del nombre de pasajeros (Directiva EU 2016/68199), y la Decisión Marco

sin referirse directamente al derecho penal, pueden tener consecuencias penales. En este sentido, por ejemplo, en lo que se refiere a las «obligaciones financieras» de Reino Unido, en la position paper «Essential Principles on Financial Settlement» TF50 (2017)-Commission to United Kingdom, de 12 de junio (https://goo.gl/cvnM1E; fecha de la última consulta: 23-10-2017), establece una retirada de la Unión Europea paulatina en el marco de la programación financiera del período 2014-2020, distinguiendo obligaciones que deberán seguir siendo compartidas por la Unión Europea y Reino Unido. En particular deben tenerse en consideración sus disposiciones a los efectos de valorar la eventual comisión de delitos que afectan a los intereses financieros de la Unión, después del brexit.

88 TF50 (2017)8-Commission to EU 27, de 28 de junio.

89 TF50 (2017) 8/2-Commission to UK, de 12 de julio.

90 DO L 130, de 1 de mayo de 2014 (p. 1).

91 DO L 190, de 18 de julio de 2002 (p. 1).

92 DO L 328, de 22 de noviembre de 2006 (p. 95).

93 DO L 76, de 22 de marzo de 2005 (p. 16).

94 DO L 337, de 16 de diciembre de 2008 (p. 102).

95 DO L 24, de 23 de enero de 1998 (p. 1).

96 DO L 93, de 7 de abril de 2009 (p. 33).

97 DO L 338, de 21 de diciembre de 2011 (p. 2).

98 DO L 386, de 28 de diciembre de 2006 (p. 71).

99 DO L 119, de 4 de mayo de 2016 (p. 132). 
2007/845/JAI sobre cooperación entre oficinas de blanqueo de capitales ${ }^{100}$. Se trata de las decisiones de la UE que Reino Unido, en uso de los atributos que le confiere el Protocolo 21 del Tratado de Lisboa ha decidido adoptar y, como se ve, no son pocas ni irrelevantes. En cualquier caso, el acuerdo se limita a establecer la vigencia del derecho europeo para los procedimientos «en curso", porque se sobreentiende que en un futuro no existirán procedimientos comunes a los que aplicarles estos institutos procesales-penales.

Pero como se decía, después de que la UE dirigiera ese acuerdo a los veintisiete Estados miembros el 28 de junio, el 12 de julio se le da traslado a Reino Unido $^{101}$. El contenido es el mismo, aunque se añaden algunas previsiones de interés sobre el principio non bis in idem. Así, se afirma que «esto incluye la toma en consideración, en el curso de los procedimientos criminales contra una persona, de una condena anterior dictada contra la misma persona por hechos diferentes en otro Estado miembro, respecto a los cuales la información haya tenido que ser obtenida bajo instrumentos aplicables de asistencia legal mutua o en el intercambio de información extraída de los antecedentes penales, como se prevé en la Decisión Marco del Consejo 2008/675/JAI» ${ }^{102}$. Paradójicamente, esta es la única previsión de contenido penal que puede ser resaltada en los documentos conocidos hasta la fecha: el hecho de que se incluya en una mera nota al pie aclaratoria y que se refiera más al derecho penitenciario que penal subraya la idea de que en las negociaciones el peso del derecho penal sustantivo europeo ha brillado por su ausencia. Nada se dice sobre los casos que estén pendientes, como sí se hace en el documento TF50 (2017) Commission to EU 27 de 24 de mayo, que contiene el Working paper on Essential Principles on Citizens' Rights ${ }^{103}$, que establece que esos principios se van a aplicar «también a la interpretación que haya de hacerse en los casos pendientes a la fecha de la salida por parte de los tribunales competentes, que será mantenida de conformidad con el Acuerdo de retirada».

Por su parte, en el documento del Grupo de trabajo TF50 (2017) 17 Commission to EU 27, de 28 de septiembre, sobre Citizens' rights a fin de conseguir la residencia, se hacen tres previsiones específicas de contenido penal ${ }^{104}$. Respecto a la «criminalidad cometida pre-exit» existe acuerdo en

100 DO L 332, de 18 de diciembre de 2007 (p. 103).

101 Véase https://goo.gl/cvnM1E (fecha de la última consulta: 23-10-2017).

102 DO L 220, de 15 de agosto de 2008 (p. 32). Sobre el principio non bis in idem en el ámbito del TEDH y del TJUE, véase García Rivas (2017).

103 Cuyo contenido se repite en el documento TF50 (2017) Commission to UK, de 12 de junio de 2017, Position paper on Essetial Principles on Citizens' rights. Disponible en: https://goo.gl/cvnM1E (fecha de la última consulta: 23-10-2017).

${ }^{104}$ Hay varios documentos de trabajo previos a este de 20 de julio: TF50 (2017) 10 Commission to EU 27 y de 31 de agosto y TF50 (2017) 16 Commission to EU 27, 
remitirse a la Directiva 2004/38 en materia de seguridad pública, policía y salud. Hay que resaltar que en los documentos anteriores se hacía mención expresamente a la «expulsión por razones de seguridad pública, política o salud según la Directiva 2004/38». Sin embargo, el documento final parece que suaviza la respuesta al eliminar literalmente la palabra «expulsión», que vuelve a aparecer sin embargo en la directiva a la que remite.

La segunda referencia penal es la que se realiza a la "criminalidad cometida post-exit». En este caso sigue sin encontrarse un acuerdo, en la medida en que la propuesta de la UE es remitirse también a lo dispuesto en la Directiva 2004/38 añadiendo «basado en una evaluación individual», a fin de evitar que la expulsión se convierta en la respuesta automática frente a los delitos cometidos después de la salida de la Unión, mientras que Reino Unido defiende «la expulsión por las actividades post-exit bajo la evaluación de las reglas de inmigración de Reino Unido», que sin muchas dudas serán muy duras y convertirán la expulsión en regla.

El mismo documento refleja el estado de las negociaciones sobre procedimientos administrativos y criminalidad: la posición de la UE es que «los controles de la delincuencia no pueden realizarse sistemáticamente», mientras que Reino Unido es partidario de aplicar controles sistemáticos sobre la criminalidad y de «preguntar a los solicitantes que declaren sobre aspectos relativos a los antecedentes penales». La falta de acuerdo hace necesario seguir trabajando en este punto.

Y aquí acaban las cuestiones más relacionadas con temas penales contenidos en las primeras negociaciones. Si se comparan cuantitativa y cualitativamente con las materias penales a las que se refiere el art. 83.2 TFUE, y que han sido analizadas anteriormente, puede decirse que quedan muchas cuestiones por cerrar antes del acuerdo final de salida.

\section{LOS EFECTOS DEL BREXIT EN EL SISTEMA ACTUAL DEL COMMON LAW}

Pero dentro del propio ordenamiento jurídico de Reino Unido, las consecuencias del brexit se van a dejar notar en el sistema de fuentes ${ }^{105}$. En efecto,

en los que se ha ido avanzando poco a poco en estas materias, a pesar de que aún quedan cuestiones por acordar. Disponible en https://goo.gl/cvnM1E (fecha de la última consulta: 23-10-2017).

105 Sobre las similitudes y diferencias procesales entre los sistemas de common law y de civil law, véase por todos Jimeno-Bulnes (2013: 207 y ss.). Como se señalará a conti- 
como es sabido, el sistema de common law se caracteriza porque no rige el principio de legalidad, ni las garantías inherentes al mismo en ordenamientos jurídicos como el español, que lo consagra en el art. 25 de la Constitución ${ }^{106}$, como la irretroactividad de las disposiciones desfavorables para el reo o la culpabilidad por un hecho sobre el que no siempre habrá certeza de que se conoce su ilicitud. Se trata de un sistema en el que son los jueces, a través de la jurisprudencia, quienes verbalizan las normas (rules) ${ }^{107}$. Con todo, como afirman Card y Molloy $(2014,14)$, «a pesar de que los jueces tiene el poder de hacer leyes, no tienen el poder de crear nuevos delitos o de ampliar los delitos existentes, así como hacer punibles conductas de una clase que no sea previsible su castigo", por lo que en la actualidad es el Parlamento el que se encarga de aprobar estas leyes más complejas que exige el control de una delincuencia cada vez más tecnificada ${ }^{108}$ : basta pensar en delitos como el stalking, las

nuación en lo referido al derecho penal, la autora entiende que a día de hoy tampoco «existe un proceso penal "puro» en estos momentos, en la medida en que todos los diversos sistemas procesales penales son producto de la interrelación y combinación de las diferentes tradiciones legales» (p. 212). Tras el análisis detenido que lleva a cabo sobre las características de uno y otro sistema procesal concluye resaltando que el acercamiento entre ambos procesos se ha producido en la actualidad tras una progresiva influencia del proceso penal norteamericano en los procesos europeos (p. 301). Véase también Bachmaier Winter (2008: 13). En extenso, véase Armenta Deu (2012: especialmente 19-41).

${ }^{106}$ Herring (2017: 32) se refiere a los intentos habidos en Reino Unido por aprobar un Código Penal, aunque ese proyecto se abandonó en 2008, momento en el que «quizás quedó claro que el Parlamento no tenía tiempo ni motivación para llevar a cabo una revisión completa del derecho penal». A favor de la creación de un Código penal arguye que promovería «la accesibilidad, comprensión, conocimiento y certeza», mientras que entre sus críticas afirma que "un Código puede ser obsesivo con las guías principales y consistencia interna y pasando por alto el hecho de que la aparente contradicción con la ley penal puede reflejar la complexión de muchas políticas, y usos éticos y prácticos desarrollados». Véase también Wilson (2011: 23).

107 Ashworth y Horder (2013: 8); véase también Padfield (2014: 15). Con razón afirma Leonard (2017: 3) que uno de los motivos de mayor peso que dificulta las relaciones entre España y Reino Unido es la diferencia que existe en sus respectivos sistemas procesales.

108 Véanse los ejemplos de Wilson (2011: 19-20), cuando describe los motivos que justificaron la aprobación de la Sexual Offences Act de 1976, en la que se aclaran modalidades de agresión sexual distintas al coito vaginal. Armenta Deu (2012: 25) se refiere a la necesidad en el sistema de civil law (o inquisitivo) de que el juez juzgue, y no tenga "facultades legislativas directas o indirectas". 
conductas relativas a las drogas o la ocupación ilegal de viviendas (Card y Molloy, 2014: 20) (statute law o overruling ${ }^{109}$ ).

Pues bien, en muchos casos el motor que ha impulsado la aprobación por el Parlamento de esas leyes escritas ha sido la $\mathrm{UE}^{110}$, en la medida en que Reino Unido ha tenido que ratificar por medio de una ley cada una de las normas a implementar. Por ello, puede decirse que la principal consecuencia del brexit en el ámbito del sistema de fuentes de Reino Unido es que deja de ser necesario aprobar las leyes parlamentarias que, al tiempo que han venido a servir de instrumento de ratificación de las normas procedentes de la UE, han dado forma a un cuerpo de leyes escritas, expresión de la voluntad del Parlamento, esto es, al principio de legalidad y a las garantías que le son inherentes.

Por tanto, tras el brexit las normas penales de Reino Unido positivizadas en una ley que tiene su origen en el derecho europeo ${ }^{111}$, como en el cohecho, el tráfico de drogas, en materia medioambiental, terrorismo, evasión del IVA y fraudes fiscales, tráfico ilícito de personas, prostitución y pornografía infantil, materias que, en definitiva, son consecuencia de «la implementación de la legislación de la UE lleva aparejada la mayoría de los nuevos delitos en la ley inglesa cada año» (Card y Molloy, 2014: 20), dejan de tener sentido y justificación. Como ya señalaba la carta de Theresa May, el Parlamento

109 Véase Donini (2017: 24). Muy interesante es el estudio que lleva a cabo de la analogía y de la interpretación analógica, señalando la evolución habida dentro de la legislación italiana en torno a la interpretación del concepto "cosa mueble ajena» como objeto material del delito de hurto: "Aplicar el hurto a la sustracción de computers no ha sido en su momento un acto de «invención jurídica»; pero lo habría sido (por lo demás) si no hubiese existido el "concepto» de género de las cosas muebles y hubiese existido solo colecciones de «n» casos que se aplican a $\mathrm{n}^{1}$ manzanas, $\mathrm{n}^{2}$ monedas, $\mathrm{n}^{3}$ utensilios de trabajo, $\mathrm{n}^{4}$ libros, $\mathrm{n}^{5}$ ovejas, $\mathrm{n}^{6}$ pollos, $\mathrm{n}^{7}$ pistolas, etc., pero no a los computers. $\mathrm{Al}$ mismo tiempo nadie piensa que el tipo penal aplicable a la sustracción de energía eléctrica (art. 624.2 Código penal), después de decenios de discusión teórico-práctica, sea hoy extensible a los datos informáticos («cosas muebles»), aunque si a las «cosas» provenientes de datos informáticos sustraídos ilegítimamente de un sistema, como los soportes informáticos que los contienen (disquetes, pen-drives, etc.), que son objetos materiales posibles de receptación respecto al delito presupuesto de acceso ilegal a un sistema informático (art. 615-ter Código penal): clara extensión del concepto de cosa proveniente del delito".

110 Sobre la influencia del derecho de la Unión Europea en el sistema de common law véase Weyembergh (2017: 291).

111 Al que añaden Card y Molloy (2014: 12) «la Convención Europea de Derechos humanos»: ambos instrumentos «se están convirtiendo progresivamente en importantes fuentes». 
británico dio el 12 de septiembre el primer paso para convalidar ese derecho como derecho inglés, para evitar vacíos de punición. Habrá que ver si se trata solo de una convalidación transitoria o si se convierten en derecho interno permanente. De ser así, podrá comprenderse que aunque el brexit suponga una ruptura formal de las relaciones entre la UE y Reino Unido, no supondrá una ruptura material, pues se seguirá transitando por la misma senda (Child y Ormerod, 2017: 19-20).

Este efecto secundario del brexit es muy significativo. Sin embargo, debe contextualizarse en un momento en el que los sistemas que se rigen por el principio de legalidad también han abierto la vía a la jurisprudencia para que «dé forma» o "aclare» el sentido de la ley de forma vinculante. Esto es lo que viene ocurriendo en nuestro país, cada vez que el Tribunal Supremo adopta acuerdos no jurisdiccionales que carecen de efectos retroactivos sobre puntos muy relevantes en materia penal ${ }^{112}$.

En definitiva, puede afirmarse pues que a pesar de las enormes diferencias existentes entre ambos modelos, en la actualidad se está produciendo tal acercamiento, que ni uno ni otro es un modelo puro: están bridados por las

112 Sobre el cambio de criterio de interpretación judicial en torno al concepto de «notoria importancia de las drogas» objeto del delito de tráfico de drogas y sus efectos en el ámbito de la determinación de la pena, véase Acale Sánchez (2002: 201 y ss.). Por otra parte, es muy interesante resaltar en este sentido lo sucedido en España con la conocida como doctrina Parot. Mientras se consolidaba la aplicación jurisprudencial de las reformas operadas por las leyes orgánicas 7/2003 y 5/2010, y mientras se tramitaba ya el proyecto de reforma de la hoy Ley Orgánica 1/2015, el TEDH hizo pública su Sentencia de 21 de octubre de 2013 (Caso Del Río Prada v. España, número de recurso 42750/09) y declaró contraria al Convenio de Derechos Humanos la doctrina Parot, construcción jurisprudencial «creada» a partir de la STS de 28 de febrero de 2006 [RJ 2006/467], que ha permitido durante estos años la prolongación del tiempo de estancia en prisión para personas condenadas por una pluralidad de delitos en atención al Código Penal de 1973. Los motivos alegados por el TEDH para declarar contraria al Convenio esta interpretación jurisprudencial española han sido la violación del derecho a la libertad y a la seguridad (art. 5) y la vulneración del principio de legalidad (art. 7). La firma de esta sentencia provocó la puesta en libertad de las personas que estaban privadas de libertad según la famosa doctrina. En ese momento se desató la alarma social, por el riesgo de que volvieran a delinquir: pasados estos años, se ha podido comprobar que el índice de reincidencia de estos sujetos ha sido escasísimo. La opinión pública no tuvo en consideración la necesidad de estas personas de terminar de vivir el resto de sus vidas fuera de prisión, aprovechándose de un resquicio que les ofrecía el Estado de derecho, al que muchas de ellas no habían respetado. 
influencias que recíprocamente se procesan ${ }^{113}$ (Armenta Deu, 2012: 23; Jimeno-Bulnes, 2013: 301).

Con independencia de esto, el hecho de que desaparezca la obligación de Reino Unido de aprobar leyes que cumplan con los mandatos de la UE hace que disminuyan los motivos (excusas, si se quiere, desde el punto de vista que aquí interesa) para aprobar leyes escritas.

\section{REFLEXIONES FINALES}

El estado actual en el que se encuentran las negociaciones entre Reino Unido y la UE no permite que se puedan extraer "conclusiones» definitivas sobre los efectos del brexit en la política criminal, en la medida en que más allá del reconocimiento de la escasa importancia que estas materias han tenido hasta este momento es difícil aventurar el alcance de los acuerdos de cooperación que a todas luces parece que tendrán que firmarse, por una parte, entre Reino Unido y la UE, y por otra, entre cada uno de los países miembros y Reino Unido, pues todos estos años de convivencia dentro de la misma entidad política impiden que se pueda pasar de página sin mayores consecuencias ${ }^{114}$.

Una solución podría ser, respecto a las materias de libertad, seguridad y justicia, que Reino Unido mantenga el status actual y decida qué acuerdos quiere firmar. De esa forma, el brexit no llevaría aparejado un trato más favorable "nuevo», porque actualmente es así, aunque con la gran diferencia de que hasta ahora es miembro de la UE y después del brexit dejará de serlo. Todo dependerá del alcance de miras y la grandeza con la que el resto de los Estados miembros y la UE sean capaces de afrontar el problema de la salida de uno de sus miembros. Y sería una forma de mantener la necesaria unidad en la UE y entre los Estados miembros en estas materias: a la vista están los modelos que representan Suiza y Noruega.

Con todo, si se tiene en consideración la especial posición de Reino Unido dentro de la UE, que le ha permitido seleccionar las directivas en materia penal a las que vincularse, optando por unas materias y rechazando otras, su salida de la Unión no va a ser de la misma envergadura que si saliera otro Estado vinculado

113 Un profundo estudio comparado entre los sistemas de common law y de civil law puede verse en Donini (2017, 14 y ss.). El autor analiza las causas del difícil diálogo que puede mantenerse entre ambos sistemas, destacando las diferencias entre derecho y ley, conocimiento del derecho, retroactividad y analogía.

114 Algunas pistas ofrece Leonard (2017: 8) sobre los factores que pueden determinar la puerta de salida. 
por el conjunto de instrumentos que integran el espacio de libertad, seguridad y justicia; por tanto, desde el punto de vista de la UE, puede decirse que se amortiguan los efectos institucionales y materiales que la salida de otro país sí que produciría: recuérdese que de las materias penales «esenciales» a las que se ha hecho referencia anteriormente, Reino Unido ha optado por no vincularse a la Unión en materia de terrorismo; sí lo ha hecho abiertamente en blanqueo de capitales; no así en el ámbito de la protección de los intereses financieros, aunque el hecho de no haberse vinculado a la última directiva no le exime de velar por esos intereses en atención a lo dispuesto el Convenio de 1995, al tiempo que sí ha optado por vincularse en cuanto a los sistemas de información. El conjunto de decisiones adoptadas por Reino Unido nos permite plantearnos si las decisiones que singularmente ha ido adoptando (en relación con cada una de estas materias) han obedecido a un mismo patrón político criminal — por ejemplo, la necesidad de perseguir en consonancia con la UE la delincuencia- o si por el contrario obedecen a otros motivos políticos - no político-criminales- coyunturales no tan confesables.

Y si, por otro lado, se resalta ahora el interés detectado tanto en la Cámara de los Lores como en la Cámara de los Comunes de proceder a la firma de acuerdos puntuales que permitan a Reino Unido participar activamente en el entramado procesal europeo, no deja de sorprender, como afirma Mitsilegas (2017a: 246), que lo que más reticencia dio al nacer la UE, la cesión soberana de competencias en materia penal, sea lo que finalmente quiera mantener Reino Unido —aunque sea "caso a caso», como una «justicia a la carta» o "pick-and-choose»- ${ }^{115}$.

En cualquier caso, debe dejarse señalado que la salida del Reino Unido de la UE no parece estar relacionada con la cesión de soberanía en materia penal (Mitsilegas, 2017a: 249), en la medida en que no hubo tal cesión cuando procedió a la firma del Tratado de Lisboa, con la firma del Protocolo 21.

Con todo, al margen del dato objetivo de la pérdida de un país de la UE, si se mira de forma optimista el proceso se puede adelantar ya la conclusión principal de este trabajo: y es que el hecho de que no se haya producido la salida por motivos penales, robustece el poder penal que sigue teniendo la UE, actualizando su legitimidad política. Solo queda esperar que esas competencias penales se ejerzan respetando los derechos humanos de los ciudadanos de la Unión y de quienes intentan vivir en ella.

115 Puede verse Mitsilegas (2017b: 437-438), donde el autor afirma que es posible que tras el brexit el Reino Unido se vea en la paradójica posición de «tener que aceptar más leyes de la Unión Europea que las que acepta en la actualidad como estado miembro de la Unión». 


\section{Bibliografía}

Acale Sánchez, M. (2001). Las subvenciones comunitarias y sus fraudes. En J. M. Terradillos Basoco (coord.). Protección de los intereses financieros de la Unión Europea (pp. 43-70). Madrid: Trotta.

— (2002). Salud pública y tráfico de drogas. Valencia: Tirant lo Blanch. (2007). Previsiones sancionadoras en la Decisión Marco del Consejo, de 13 de junio de 2002, sobre la lucha contra el terrorismo y su transposición al Derecho penal español. En N. García Rivas (ed.). El Derecho penal frente a la inseguridad global (pp. 217-256). Albacete: Bomarzo.

- (2008). Derecho penal y Tratado de Lisboa. Revista de Derecho Comunitario Europeo, 30, 349-380.

Ambos, K. y Bock, S. (2017). Preface by the Symposium Editors. Criminal Law Forum, 28 (2), 183-185.

Armenta Deu, T. (2012). Sistemas procesales penales. La justicia penal en Europa y América. Madrid, Barcelona, Buenos Aires: Marcial Pons.

Ashworth, A.y Horder, J. (2013). Principles ofCriminalLaw. Oxford: Oxford University Press. Disponible en: https://doi.org/10.1093/he/9780199672684.001.0001.

Asp P. y otros (2009). Manifiesto sobre la política criminal europea. Zeitschrift für Internationale Strafrechtsdogmatik,12. Disponible en: www.zis.online.com.

Bachmaier Winter, L. (2008). Acusatorio versus inquisitivo. Reflexiones acerca del proceso penal. En L. Bachmaier Winter (coord.). Proceso penal y sistemas acusatorios (pp. 11-48). Madrid, Barcelona, Buenos Aires: Marcial Pons.

Bock, S. (2017). Brexit and the future of European Criminal Law: a German perspective. Criminal Law Forum, 28, 311-318. Disponible en: https://doi. org/10.1007/s10609-017-9315-x.

Cahn, O. (2017). Brexit and the future of European criminal Law. A French perspective. Criminal Law Forum, 28, 301-309. Disponible en: https://doi. org/10.1007/s10609-017-9309-8.

Card, R. y Molloy, J. (2014). Criminal Law. Oxford: Oxford University Press.

Child, J. y Ormerod, D. (2017). Essentials of Criminal Law. Oxford: Oxford University.

Del Valle Gálvez, A. (2017). Brexit negotiations and Gibraltar: time for 'a modus operandi'? Cuadernos de Gibraltar. Gibraltar Reports, 2016-2017, 19-26.

Donini, M. (2003). Sussidiarietà penale e sussidiarietà comunitaria. En M. Donini (ed.). Alla recerca di un disegno. Scritti sulle riforme penale in Italia (pp. 115165). Milano: Cedam.

— (2017). An impossible Exchange? Prove di dialogo tra civil e common lawyers su legalitá, morale e teoria del reato. Rivista Italiana di Diritto e Procedura, 1, 14-47.

Escobar Hernández, C. (2016). Brexit: algunas reflexiones desde el derecho internacional. Revista Española de Derecho Internacional, 68 (2), 19-22. 
Faraldo Cabana, P. (2014). Improving the recovery of assets resulting from Organised Crime. European Journal of Crime, Criminal Law and Criminal Justice, 13-32. https://doi.org/10.1163/15718174-22012037.

García Rivas, N. (2017). Alcance y perspectivas del ne bis in idem en el espacio jurídico europeo. Revista General del Derecho Penal, 27.

Herring, J. (2017). Criminal Law. Oxford: Palgrave Law Masters.

Jimeno-Bulnes, M. (2008). Orden europea de detención y entrega: garantías esenciales. Revista Aranzadi de Derecho y Proceso Penal, 19, 13-32.

(2013). El proceso penal en los sistemas del common law y civil law: los modelos acusatorio e inquisitivo en pleno siglo XXI. Justicia, 2, 207-310.

- (2017). Brexit and the future of European Criminal Law. A Spanish perspective. Criminal Law Forum, 28, 325-347. Disponible en: https://doi.org/10.1007/ s10609-017-9312-0.

Leonard, B. (2017). Judicial cooperation with United Kingdom. Some references to the consecuences of «Brexit». En Los retos del espacio de Libertad, Seguridad y Justicia de la Unión Europea en el año 2016: Reunión anual REDPE.

Mangas Martín, A. y Liñán Nogueras, D. J. (2015). Instituciones y Derecho de la Unión Europea. Madrid: Tecnos.

Meško, G. (2017). Police cooperation in the European Union, supported by strengthening the EU internal security's external dimension. European Journal of Crime, Criminal Law and Criminal Justice, 25, 109-121. Disponible en: https://doi.org/10.1163/15718174-25022108.

Meyer, F. (2017). The 'Swiss model' as an option for the future UK-EU relationship. Criminal Law Forum, 28, 275-299. Disponible en: https://doi.org/10.1007/ s10609-017-9313-z.

Mitsilegas, V. (2016). EU Criminal Law after Lisbon. Oxford: Hart Publishing.

— (2017a). European criminal law after Brexit. Criminal Law Forum, 28, 219250. Disponible en: https://doi.org/10.1007/s10609-017-9314-y.

(2017b), European criminal law without the United Kingdom? The triple paradox of Brexit. New Journal of European Criminal Law, 8 (4), 437-438. Disponible en: https://doi.org/10.1177/2032284417743819.

Monty, R. (2016). Bribery. Law and Practice. Oxford: Oxford University.

Nieto Martín, A. (1996). Fraudes comunitarios. Derecho penal económico europeo. Barcelona: Praxis.

— (1998). La lucha contra el fraude a la Hacienda pública comunitaria: de la asimilación a la unificación. En C. Martínez-Buján Pérez (dir.). I Congreso hispano-italiano de Derecho Penal Económico (pp. 183-250) A Coruña: Ediciones de la Universidad de A Coruña.

- (2006). Principio de doble incriminación y lista de eurodelitos: la corrupción como ejemplo. En Publicaciones del Portal Iberoamericano de las Ciencias Penales. Instituto de Derecho Penal Europeo e Internacional, Universidad de Castilla-La Mancha. Disponible en: www.cienciaspenales.net.

Ouwerkerk, J. (2015). Criminal justice beyond national sovereignty. An alternative perspective on the europeanisation of Criminal Law. European Journal of 
Crime, Criminal Law and Criminal Justice, 23, 11-31. Disponible en: https:// doi.org/10.1163/15718174-23012058.

Padfield, N. (2014). Criminal Law. Oxford: Core Text Series. Disponible en: https:// doi.org/10.1093/he/9780198704164.001.0001.

Picotti, L. (2006). La lucha contra el fraude del presupuesto de la Unión Europea desde la perspectiva de la Constitución Europea. En M. Bajo Fernández, S. Bacigalupo y C. Goméz-Jara Díez (coords.). Constitución Europea y Derecho penal económico, (pp. 41-88). Madrid: Editorial Universitaria Ramón Areces.

Pieth, L. (2007). The OECD Convention on Bribery. Cambrige: Cambridge University Press. Disponible en: https://doi.org/10.1017/CBO9780511494307.

Quintero Olivares, G. (2017), Sobre posibles consecuencias penales del Brexit. Revista de Derecho y Proceso Penal, 45.

Ramses Wessel, L. y Marín Claudrio, M. (2011). The external dimension of the EU's Area of Freedom, Security and Justice. En C. Eckes y T. Konstadinides (coords.). Crime within the Area of Freedom, Security and Justice. A European Public Order, (pp. 272-300). Cambridge: Cambridge University Press. Disponible en: https://doi.org/10.1017/CBO9780511751219.011.

Rodríguez Puerta, M. J. (2009). La política europea en materia de comiso. En J. M. Tamarit Sumalla (coord.). Las sanciones penales en Europa (pp. 399-436). Pamplona: Aranzadi.

Solar Calvo, P. (2016). Consecuencias penales del Brexit. LegalToday, 18-7-2016.

Suominen, A. (2017). Brexit an EU Criminal Law. The Norwegian approach. Criminal Law Forum, 28, 251-273. Disponible en: https://doi.org/10.1007/s10609017-9311-1.

Swiatlowska, A. y Nita-Swiatlowska, B. (2017). Brexit and the future of European Criminal Law- a polish perspective. Criminal Law Forum, 28 (2), 319-324. Disponible en: https://doi.org/10.1007/s10609-017-9310-2.

Tamarit Sumalla, J. M. (2009). Sanciones penales, derecho comparado y política criminal europea. En J. M. Tamarit Sumalla (coord.). Las sanciones penales en Europa (pp. 21-56). Pamplona: Aranzadi.

Terradillos Basoco, J. M. (2005). La Constitución para Europa: un reto político-criminal. Revista de Derecho Comunitario Europeo, 20, 21-45. Disponible en: https://doi.org/10.17230/nfp.12.87.1.

— (2015). Corrupción, globalización y derecho penal económico. En J. C. Ortiz Pradillo, E. Demetrio Crespo y E. González Cuéllar Serrano (dirs.). Halcones y palomas (pp. 15-51). Madrid: Ediciones Jurídicas Castillo de Luna.

— (2016). Terrorismo yihadista y política criminal del siglo XXI. Nuevo Foro Penal, $87,18-59$.

Tiedemann, K. (1999). La frode alle sovvenzioni: origine di un Diritto Penale Europeo? Rivista Trimestrale di Diritto Penale dell'economia, 3, 566-600.

Vervaele, J. (1992). Fraud against the Community. Deventer, Boston: Kluwer Law and Taxation Publisher.

Walker, C. (2011). Terrorism and the Law. New York: Oxford University. (2014). The Anti-Terrorism Legislation. New York: Oxford University. 
Weyemberg, A. (2004). L'harmonisation des législations: condition de l'espace pénal européen et révélateur de ses tensions. Bruxelles: Bruylant.

- (2017). Consequences of Brexit for European Union criminal law. New Journal of European Criminal Law, 8 (3), 284-299. Disponible en: https://doi. org/10.1177/2032284417721286.

Wilson, W. (2011). Criminal Law. Wales: Pearson. 